\title{
الغرب وظاهرة الإسلاموفوبيا
}

(المفهوم ـ النشأة ـ الأسباب ـ المظاهر ـ النتائج)

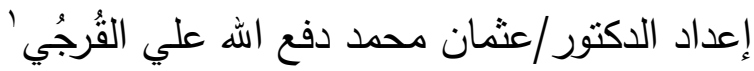

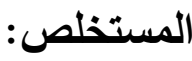

لم تمنع كثرة القراءات وتعدد التحليلات والتفسيرات لطبيعة العلاقة القائمة بين

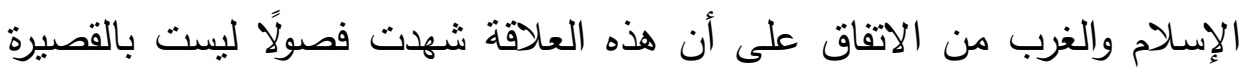

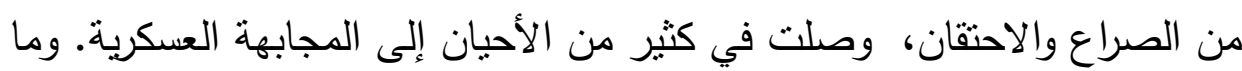

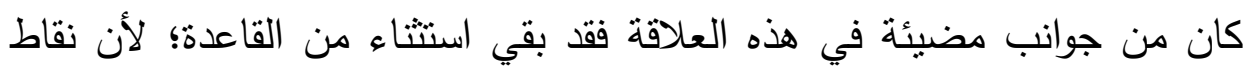

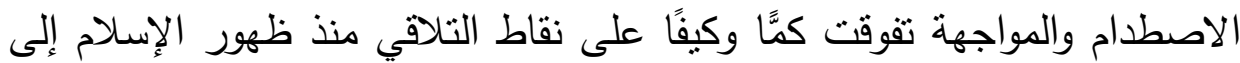

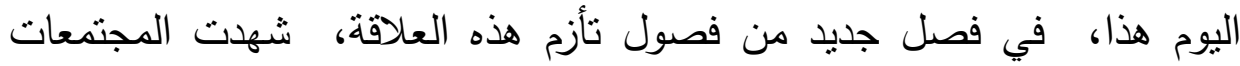

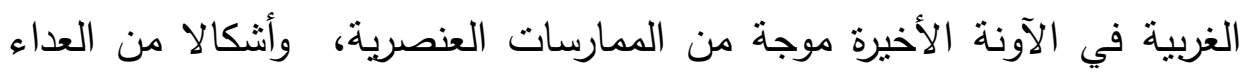

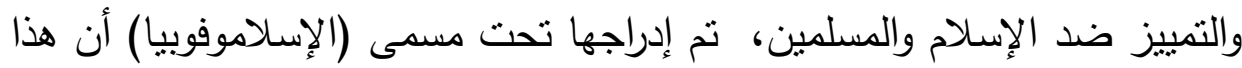
البحث يرصد العديد من الوقائع التي تثهر بكراهية الغربي للمسلمين والعرب

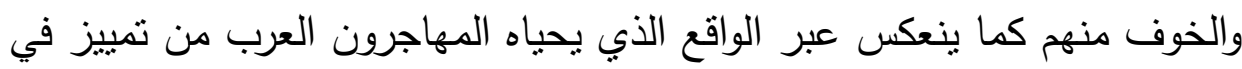
الدول الغربية.وينقل كذلك وقائع تركز عليها وتستغلها الآلة الإعلامية الغربية

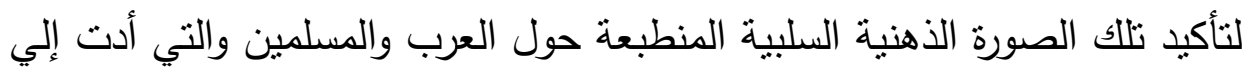

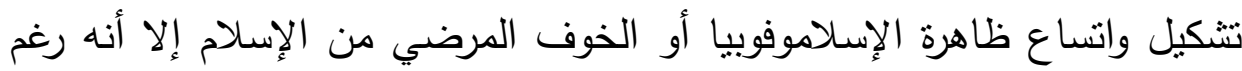
رصده لهذه الوقائع التي قام بها عرب ومسلمون واكتفي الإعلام الغربي بنقلها

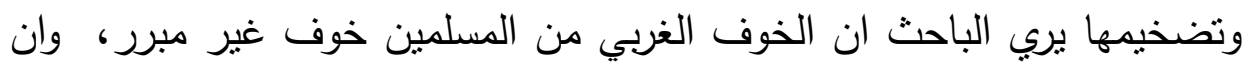

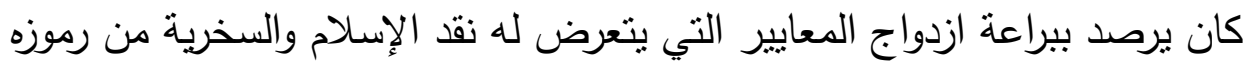

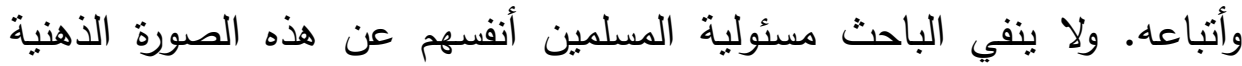
المنطبعة عنهم وان لم يعز ذلك إلي ممارستهم وخطابهم الذي يتم تصديره محملا 
بالعدوانية والكراهية والتي تقوم مؤسسات كبري في الغرب علي رصده وتسجيله.وتطرق الباحث لما قاله فلاسفة الغرب عن الإسلام والمسلمين مع توضيح الحلول التي تقارب بين هذه الفجوة. 
مجلة معالم الدعوة الإسلامية المحكمة - العدد (السابع) - ذو الحجة جبع اهـ/ ديسمبر ع ا ـ م

\begin{abstract}
:
Multiplicity of analyzes and interpretations of the nature of the relationship between Islam and the West did not prevent them from agreement. This relationship has seen for quite some time chapters of conflict and tension, arrived at to military confrontation at sometimes. The illuminated aspects of this relationship have been the exception to the rule because the collision points and confrontation excelled in quality and quantity on the points of convergence since the advent of Islam to this day. In a new chapter of the worsening of this relationship, the Western societies have seen recently wave of racist practices, and forms of hostility and discrimination against Islam and Muslims. Such practices have been listed under the name of Islamophobia. This search reports many of the facts that attest western hatred for Muslims and Arabs and the fear of them, as reflected through the reality we live, Arab immigrants suffer from discrimination in Western countries. Also, it reports and focuses on the facts which exploited by European media to confirm that the mental image of the negative impression about Arabs and Muslims, which led to the formation and expansion of the phenomenon of Islamophobia or Islamophobia. However, the research reports these deeds which were carried out by Arab and Muslims, that western media has exaggerated them. The researcher views that the western phobia from Muslims is not justified at any case. Despite the fact that the study reports the double standards of western criticism of Islam and its scholars, it does not deny the responsibility of Muslims for this distorted mental image from westerners. It did not attribute to the Muslims practices and their rhetoric which are monitored with aggressiveness and hatred by big organizations in the West.. The researcher reports what philosophers of the West said about Islam and Muslims.
\end{abstract}


المقدمة:

الحمد اله رب العالمين، والصلاة والسلام على سيدنا محمد خاتم النبيين وعلى آلة وصحبه من دعا بدعوته واهتدى بهديه إلى يوم الدين، وبعد: كل يوم

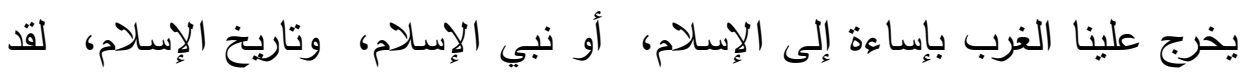

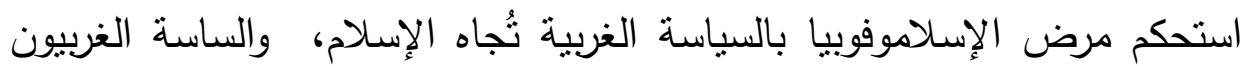

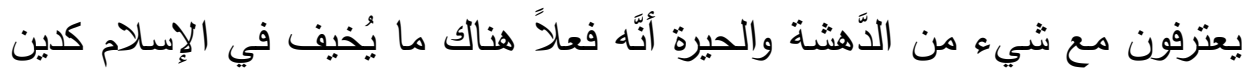
كاسح له قابلية التتامي، والانتشار بسرعة مذهلة فقد كثر الكلام عن انتشار ظاهرة خوف الكفار من الإسلام، وخوف الاتجاهات العلمانية من الحكم الإسلامي، وقام بعض المسلمين بنشر خطاب دعوي، عن الإسـام وتعاليمه ما يحاول به طمأنتهم، و وإزالة شعور الخوف والقلق من نفوسهم. 


\section{المبحث الأول}

\section{مفهوم الغرب والإسلاموفوبيا}

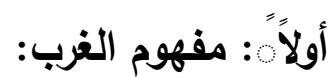

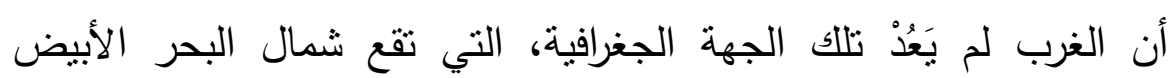

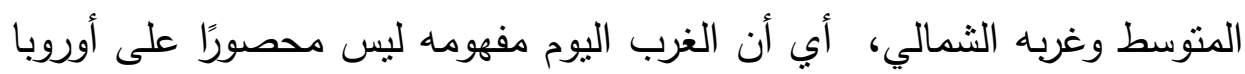

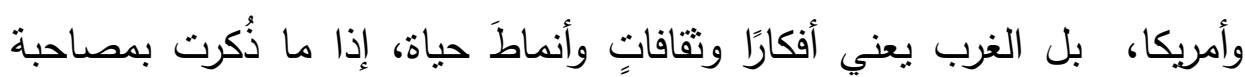

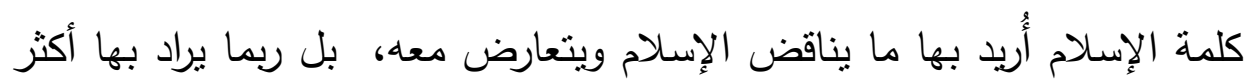
من ذلك، إذا ما نظرنا للتحديات التي يواجهها المسلمون من مفهوم الغرب. ولا يكتفي مفهوم الغرب الجديد في التوسع شرقاً حتى حدود الصين واليابان ووسط آسيا (حيث امتداد روسيا) بل إنه يضرب إلى الجنوب الأمريكي حتى القارة

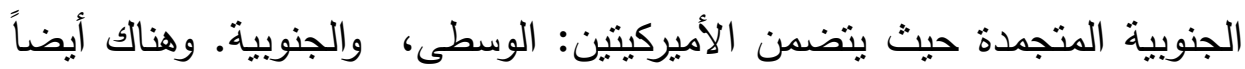

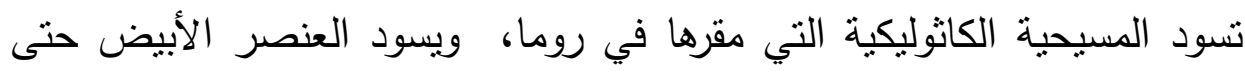

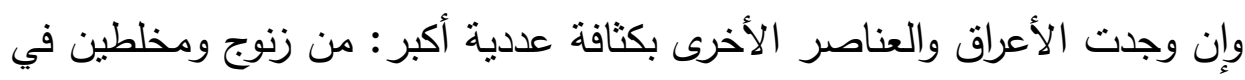

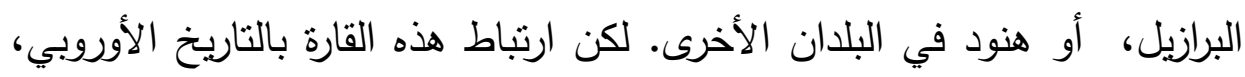

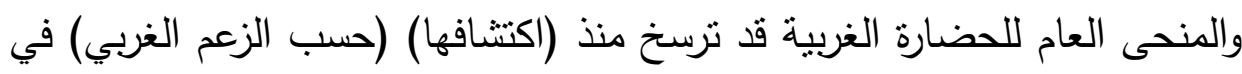
القرن الخامس عشر الميلادي، ويعاد اكتثاف هذا الإقليم الآن بثرواته وإمكاناته

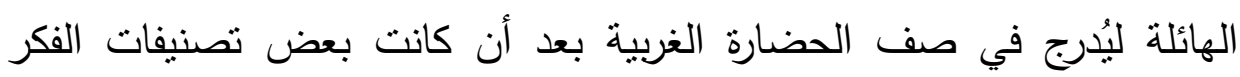
اليساري الغربي تضعه في خانة (العالم الثالث) ثم (الجنوب) في مواجهة (العالم

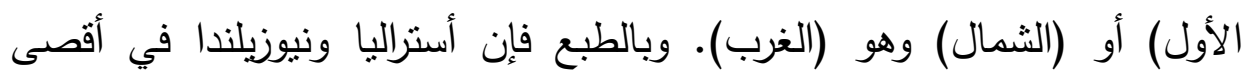
الثرق، وإلى الثرق حتى من الخصم الجديد للحضارة الغربية (الإسلام والصين 
الناهضة أو الكتلة البوذية... إلخ) تقع هي الأخرى ضمن صف الحضارة الغربية الذي تتشئه مقولة صِدام الحضارات(r).

ومن المهم فهم الغرب بهذا المفهوم، لمصلحةٍ تكمن في عدم الرغبة في حصر كرة الإسـام بالثرق، في مقابل كلمة الغرب، والإساحم اليوم في كل مكان، بما في ذلك الغرب الجغرافي، بل إنه هنالك في نمو مطّرد، يشهر عليه الإقبال المتزايد من الغربيين ذكورًا وإناثًا، بمختلف خلفياتهم العرقية والعنصرية. ولم يكن الإسلام يومًا محصورًا بالمكان، ولن يكون كذلك.

وعليه فإن الحديث عن الغرب قد يُقصد من ورائه الحديث عن أولئك الذين يتبنَّن الفكرة الغربية في النظر إلى الإسلام، وإن كان الناظرون إليه في أقصى فئ وله الثرق، بل إن كان الناظرون إليه في الوسط، حيث يتركز المسلمون العرب في الإني الجزء الغربي من قارة آسيا، والجزء الثمالي من قارة أفريقيا، دون التحديد الدقيق لهذه الأجزاء.

ومن ناحية أخرى لا يعني الغرب، جغرافيًا، مناهضة الإسلام، فليس كل

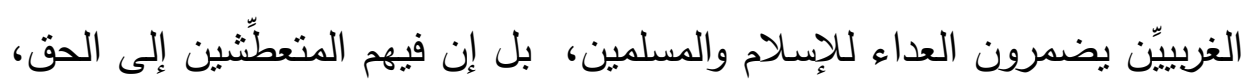

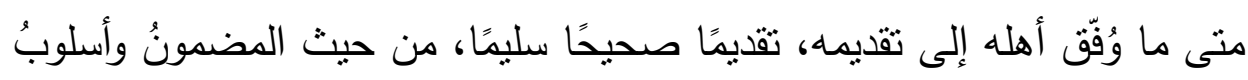
التقديم، ولذا فلا أصل لنظرة البعض في رفض كل ما هو غربي، وافتراض أنه يضمر للإسباحم والمسلمين العداء. ثانياً: مفهوم الإسلاموفوبيا

الإسلاموفوبيا (Islamophobia)هو لفظ أو مصطلح يتكون من كلمتين:

(إسلام • فوبيا)، الفوبيا في السيكولوجيا هي خوف مرضى يسيطر على وجدان الانسان الذي يعانى منه، لكن الإسلاموفوبيا هي صوره نمطية مسبقه عن الإسلام

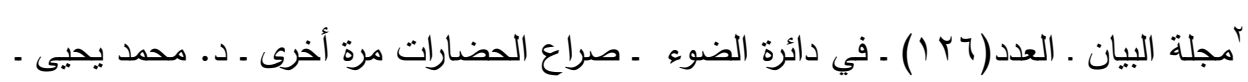
صr. 
و المسلمين تخلق كراهية و عداء للإسلام والمسلمين وتروج لها في المجتمعات الغربية أجهزة الإعلام للإثارة أو التوظيف السياسي والحركات العنصرية المتطرفة و الأحزاب والمنظمات اليمينية المتطرفة بهدف تخويف الناس من زيادة عدد المسلمين في المجتمع الغربي، ولتبربر الحروب العسكرية التي يشنها الغرب على ملى بلاد المسلمين، ومن تعريفات الإسلاموفوبيا: ا.الإسلاموفوبيا هو كل تصرف سلبى مادى أو معنوي موجه الى أشخاص مادية او معنوية تتميز بصفة إسلامية ويكون السبب الوحيد لهذا التصرف هو تلك هوي الصفة الاسلامية المشار إليها (r).. r.إن الإسلاموفوبيا هي (خوف، أو كراهية، أو عداء مبالغ فيه ضد الإسلام والمسلمين، وتقوم على صور نمطية سلبية، وتؤدي إلى التحيز ضد المسلمين والتمييز ضدهم وتهميشهم وإقصائهم من الحياة الاجتماعية والسياسية والعامة) (؛). r.يستخدم علماء الاجتماع كفيلهلم هايتماير مصطلح الإسلاموفوبيا جنبا إلى جنب مع ظواهر مثل العنصرية وكراهية الأجانب ومعاداة السامية أو حتى ظاهرة كراهية

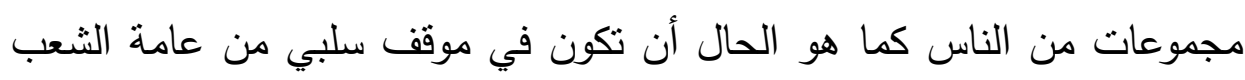
المسلم ومن جميع الأديان والرموز الدينية، وممارسات الثعائر الإسلامية(ه).

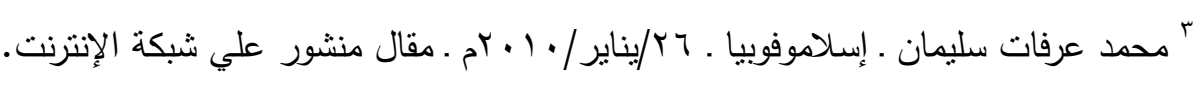
؛ علاء بيومي · جزور شبكة الإسلاموفوبيا . مقال منشور علي شبكة الإنترنت . بتأريخ . $r$. $1 \mathrm{r} / 1 / 1 \mathrm{~d}$ • أنظر لبعض الكلمات المتعلقة ,كراهية مجموعات من الناس ذات صلة فيما بينها، ومصطلح

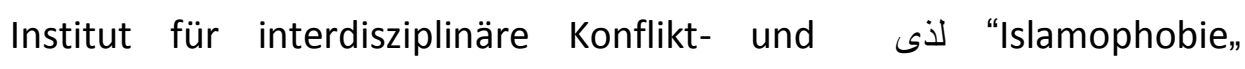
.Gewaltforschung 
ع.تعريف آخر مفصل: حسب تعريف البريطاني رونيميد تروست، هو موقف إسلاموفوبي في مجموعة متتوعة من الآراء التي يُعرّ ثَف عنها الإسلام هو كتلة وحدانية معزولة، جامدة وغير مستجيبة للتغيير (†': أ. الإسلام كتلة وحدانية معزولة، جامدة وغير مستجيبة للتغيير . ب. الإسلام مميز وغريب، وليس لديه قيم وأهداف مشتركة مع الثقافات الأخرى، لا يتأثز بها، ولكنه يؤثز فيها. ت. الإسلام أدنى من الغرب، وحشي غير عقلاني، بدائي ومتحيز ضد النساء. ث. الإسلام دين يتسم بالعنف والعدوانية، تهددي، يدعم الإرهاب وفعال في حرب الثقافات.

ج. الإسلام هو الأيديولوجية السياسية، تستعمل لأهداف سياسية أو عسكرية.

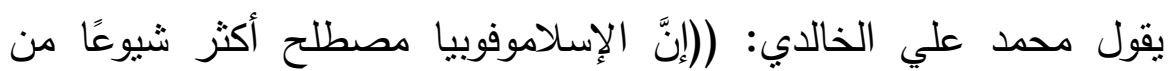
الاستشراقية. (الإسلاموفوبيا)، وقد عُرِب مصطلح الإسلاموفوبيا إلى (التخويف من الإسـام والمسلمين)، الذي يُعرَّف بأنَّه (الفزع من الإسلام أو كرهه، والخوف من المسلمين أو كرههم)، ويعتقد كثير من الخبراء أنَّ هذا المصطلح غير دقيق، ولا يعبِّر بصدق عن أنواع التمبيز ضدَّ المسلمين. ووضعه الأوروبيون على غرار مصطلح (اللاسامية)، وهي ظاهره تمبيزية أوروبية تختلف تماماً، في أجواء انبثاقها، عن نوعية العلاقة بين الإسلام والغرب. وعرَّب بعض الباحثين الإسلاموفوبيا اختصارًا بـ (إرهاب الإسلام)، ضمن ما يعتقد أنَّها سياسة حكومية تستهدف إقناع المجتمع الغربي، بوجود تتاقُض صارخ مع الإسلام، حسب مقولة أنَّ الإسلام هو الخطر الجديد القادم نحو البلدان الغربية من الثرق، بعد سقوط 
المعسكر الاشتراكي، كما عبَّر عن ذاك الأمين العام السابق للحلف الأطلسي في

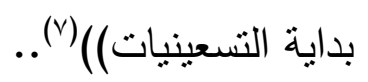

إن مفهوم (الإسلاموفوبيا) والذي يمثل أبلغ دلالة على الموقف العام في الغرب تجاه العرب والمسلمين حيث يعكس بشكل عام انتشار نزعة العداء للمسلمين، وهذه الظاهرة صنعها الإعلام الغربي الذي تملك غالبيته منظمات يهودية، وساعد أيضاً في صناعتها بعض الساسة الغربين، حيث استثروا فزاعة الإسـام والتخويف منه، لتحقيق أغراض انتخابية. ولعل أبلغ تعبير عن وضعية الإسلام في الإعلام والإدراك الغربي ظاهرة (الإسلاموفوبيا) وهي الكلمة التي دخلت قاموس السياسة الأوروبية وتحولت إلى الإنى مفردة لها معان محددة في عصرنا كما حصل في القرن التاسع عثر مع مفردة اللاسامية وتحت مفردة (الإسلاموفوبيا) وهي كلمة يقصد بها (الإرهاب الإسلامي)كمصطلح لمعنى الخوف من الإسلام بدأت تعقد المؤنمرات السياسية وتدار الندوات الفكرية لمعالجة مواضيع المخاوف من الإسلام وأبعادها الاجتماعية والاقتصادية والثقافية.

المبحث الثاني: جذور نشأة ظاهرة الخوف من الإسلام وكراهيته (الإسلاموفوبيا) موضوع الإسلام والغرب أو العالم الإسلامي وأوضاع المسلمين في الغرب شغل اهتماماً كبيراً في العقود الماضية وخاصة منذ نهاية السبعينات، وقد نشطت تلك الموجة مطلع الألفية الثالثة للميلاد(^)، وذلك الاهنمام يرجع لاعتبارات متعددة، منها بروز الثورة الإسلامية الإيرانية 9V9 (م، والجهاد في أفغانستان

http://www.mafhoum.com/p انظر : محمد علي الخالدي. إنسان بأصوات متعددّة.. resst// T $\leqslant$ CrVT.htm ^ معتز الخطيب . الغضب الإسلامي ! تفكيك العنف...دراسة نقدية . (دار الفكر:دمشق) 
.91 (م، وقضية سلمان رشدي 919 ام، ثم حرب الخليج ا99 (م، والحرب. في يوغسلافيا السابقة ب99 ام، وبروز الإسلام عاملاً سياسياً في العالم

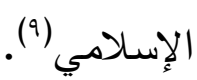

عليه نتتاول جذور نشأة ظاهرة الخوف من الإسلام وكراهيته (الإسلاموفوبيا)

$$
\text { في الآتيًً:تاريخ العلاقة بين الإسلام والغرب }
$$

ثمة ناريخ طويل يحكم نلاك العلاقة المتوترة والمتذبذبة، وقد تتبع مكسيم ردونسون (الصورة الغربية) عن الإسلام والمسلمين، وقسمها إلي محطات هي '؛ ا. العصور الوسطي التي تجلي فيها الصراع بين عالمين العالم المسيحي وعالم المسلمين، وذلك ما بين القرنين الثامن والثاني عشر الميلاديين. r. نمو وذبول صورة للإسلام أقل عداء فيما بين القرنين الثالث عثر والرابع عثر الميلاديين.

r. التعايش السلمي والتقارب؛ العدو يصبح شريكاً، وذلك ما بين القرنين الخامس عشر والسادس عشر الميلاديين. ـ ـ من التعايش السلمي إلي الموضوعية وذلك ما بين القرنين السادس عشر والسابع عشر الميلادبين. ه. ينظر الي الثرق الإسلامي نظرة أخوية متفهمة في القرن الثامن عثر الميلادي. 7 .نزعة التعلق بالغرائب والامبريالية والتخصص في القرن التاسع عثر .

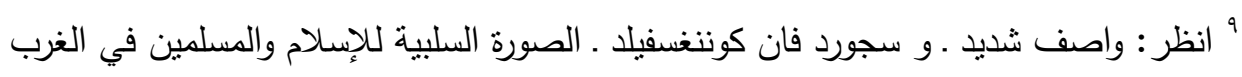

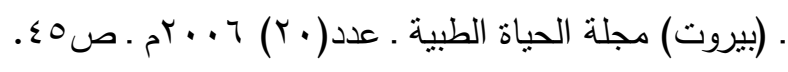

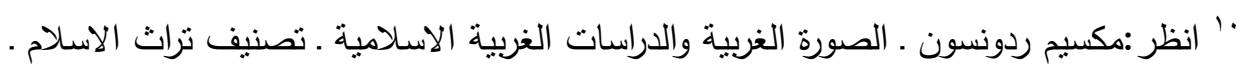

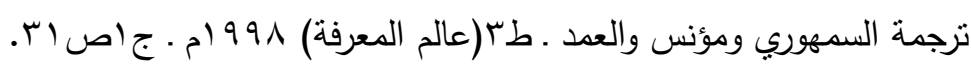


V.العصبية العرقية الاوربية تهنز في القرن العشرين.

أوجدت الحروب الصلييية حاجة كبيرة وملحة للحصول علي صورة كاملة

ومسلية ومرضية لإيديولوجيا الخصوم، وكان رجل الثارع يرغب في صورة تبين الصفة الكريهة للإِلام عن طريق تمثيله بشكله الفج، علي أن تكون في الوقت نفسه مرسومة بشكل يرضي الذوق الأدبي الميال إلي كل ما هو غريب، وهو ميل يشكل سمة بارزة في جميع الأعمال في ذلك الوقت وهكذا أخذ الكتاب اللاتينيون

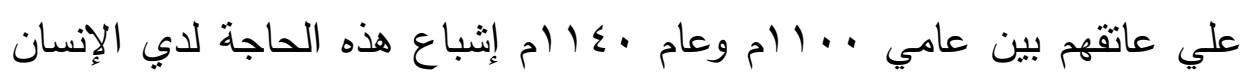

العامي، وأخذوا يوجهون اهتمامهم نحو حياة محمد دون أي اعتبار للاقة('('). هكا كانت العلاقة بين الغرب والثرق الإسلامي علاقة صراع في مسارها الرئيس، اكتقته حروب وعمليات تشويه مقصود، حركها في بدايتها وإثناءها جدالات دينية لاهوتية، ثم تحولت في القرون الأخيرة إلي علاقة تقوق وهيمنة في ظل الاستعمار والإمبريالية(r')، وفي هذا السياق يمكن إدراج مقولة الخطر الإسلامي التي سادت في الثمانينيات والتسعينيات مع ذهاب الخطر الأحمر

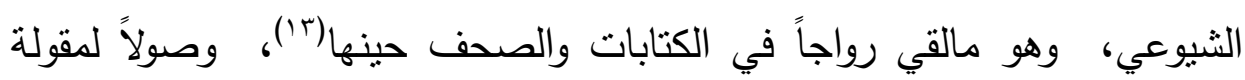
صدام الحضارات لهنتختون في منتصف التسعينيات، والتي يري فيها أن التصادم واقع بين الحضارة الإسـامية والحضارة المسيحية التي يمثلها الغرب الآن.

"' فرد دونر ـ اتجاهات الكتابة الغربية عن تاريخ الإسلام قراءة نقدية ـ (سلطنة عمان) مجلة

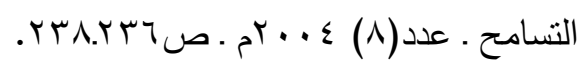
r' صوفي بسيس ـ الغرب والآخرون..قصة هيمنة ـ نرجمة نبيل سعد . طا (دار العالم الثالث:

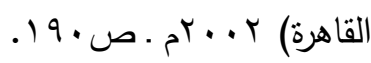

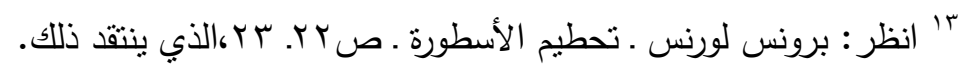
rr. 


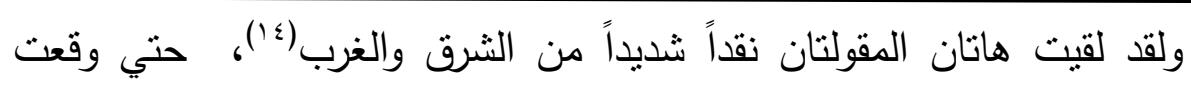

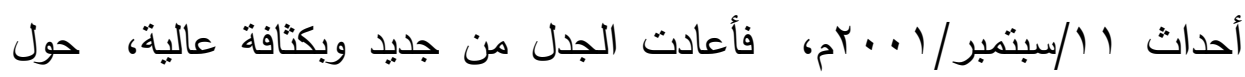
العلاقة بين الغرب والعالم الإسلامي، فظهرت مقولات (إنهم يكرهوننا) و (إنهم يكرهون العالم الحر) وصولاً لمقولة (الإرهاب الإسلامي) والربط بين الإسلام والإرهاب في حرب معلنة أطلق عليها (حرب الأفكار).

ثانياً:المسارات البارزة التي يمكن رسمها لتلك العلاقة

إن المسارات البارزة التي يمكن رسمها لتلك العلاقة تتلخص في الآتي: ا. الاهتمام الأوربي بالإسلام نشأ من الخوف من منافس للمسيحية يتميز بوحدته

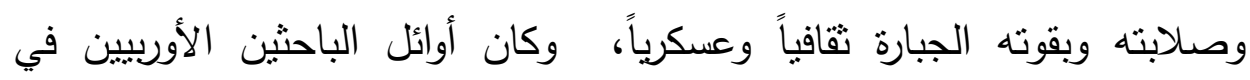
الإسلام (علي نحو ما بينه مؤرخون كثيرون) من أرباب المجادلات القروسطية الذين كتبوا ما كتبوه لدره جحافل المسلمين التي تهددهم وخطر الارتداد عن الدين المسيحي، وقد استمرت هذه التوليفة من الخوف والعداء بصورة ما حتي يومنا هذا، سواءُ في الاهتمام العلمي أو غير العلمي بالإسلام، وهو الذي ينظر إليه علي انه دين ينتمي إلي منطقة معينة من مناطق العالم (الثرق) وهي التي غدت الإن تمثل الثقل الموازن خيالياً وجغرافياً وتاريخياً لأوربا أو ضد أوربا والغرب(10).

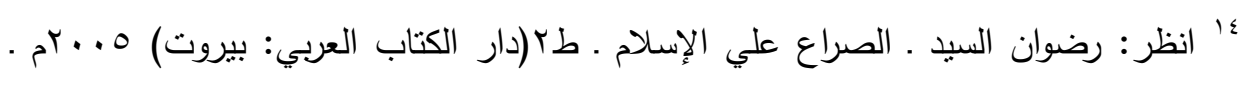

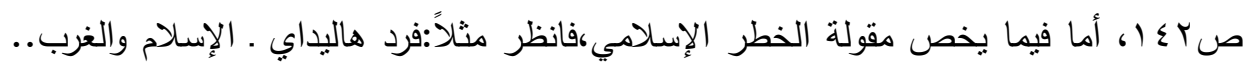

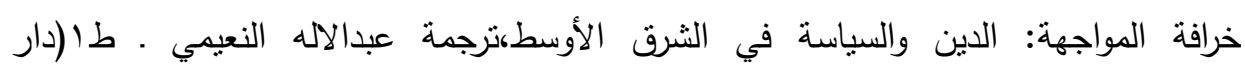

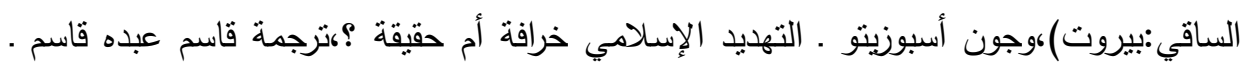

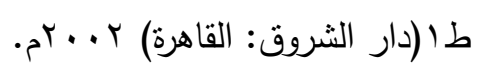

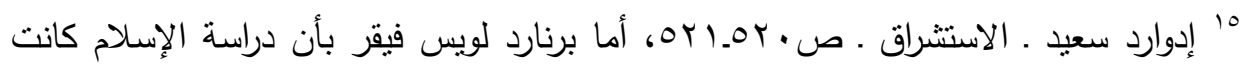

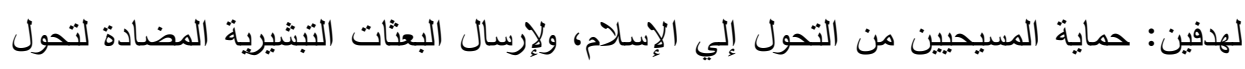

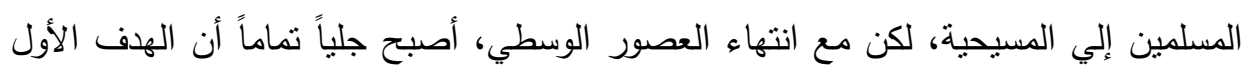


r. مسار برز فيه ثأثثر الفكر الأوربي بالفكر العربي، ثقافياً وعلمياً، وخاصة من من

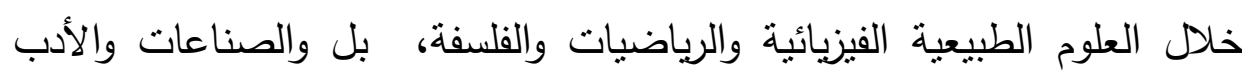

وخاصة في اسبانيا وصقلية، خاصة في القرنين الثاني عشر والثالث عشر (بات. r. مسار برز فيه الصراع السياسي بين الطرفين، وأبرز المراحل دلالة عليه هيمنة

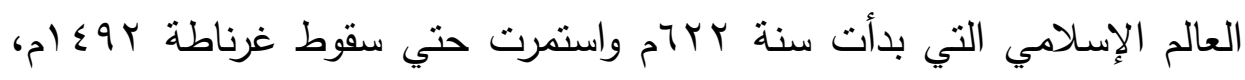
والحروب الصلييية وتهديد الإمبراطورية العثمانية لأوربا، ثم الاستعمار الغربي لأغلب العالم الإسلامي لاحقاً (V'). ء. مسار التفوق والهيمنة، والذي برزت فيه نزعة احتقار الآخر الثرقي، والتمركز الغربي حول الذات ونوازع الهيمنة علي الثرق بثرواته وثقافاته وناسه،

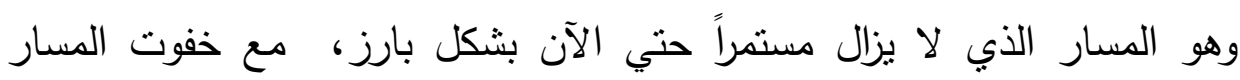
العقدي اللاهوتي، يقول تييري هنتش:(الثعور بالتفوق بات طبيعياً جداً بالنسبة

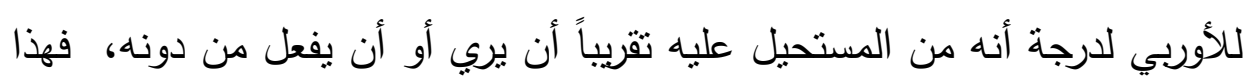
الثعور يلون كل موقفه بما في ذلك ما ينطوي عليه من حسن وفادة ومن

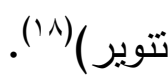

لم يعد له ضرورة وأن الهف الثاني يستحيل تحقيقه، برنارد لويس ـ الإسلام في التاريخ · ص .119 17 انظر: عبدالرحمن بدوي ـ دور العرب في تكوين الفكر الأوربي . طا (مكتبة الأسرة: القاهرة)

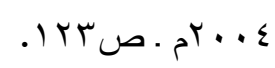
V' معتز الخطيب ـ مقال بعنوان:(ظاهرة كراهية الإسلام..الجذور والحلول) ـ مجلة ثقافتنا

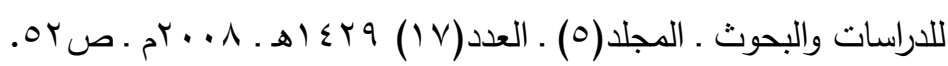

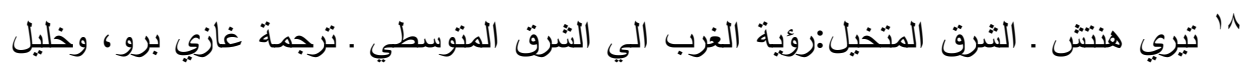

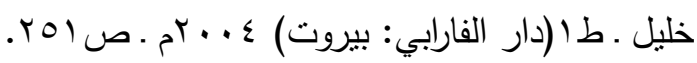
rrt 
عليه يمكن القول أن هذه الصورة بتشعباتها ومتغيراتها هدفنا منها إظهار هذه

التعقيدات والمتغيرات التي كانت تبعاً لعوامل سياسية وثقافية وفكرية داخلية، أي لي داخل الغرب نفسه خلال تطوراته الفكرية، وخارجية جراء تبدل موازين القوي. ثالثاً:الخوف الحالي من الإسلام ومصادره:

هنالك عدة عوامل لخوف الغرب من الإسلام ومنها:

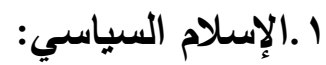

يعود هذا العامل إلي ثالثينيات القرن العشرين، مع ظهور ما يسمي

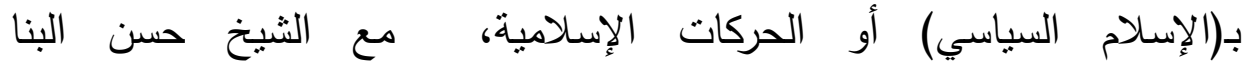

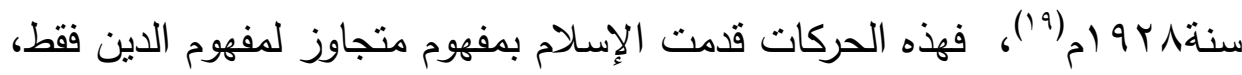
بل قدمته بوصفه (نظاماً شاملاً) اقتصادياً واجتماعياً وسياسياً وقضائياً، وبهذا يري الدارسون الغربيون أن الإسلام بهذه الصفة يتم تقديمه بوصفه أيديولوجية

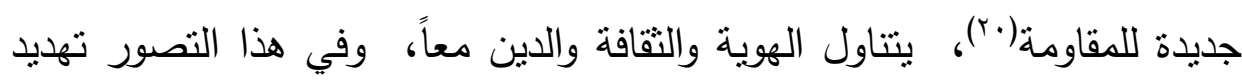
لمصالح الغرب الذي يقدم أنموذجه الحضاري علي أنه (نهاية التاريخ)، ويسعي إلي تتميط العالم وفق نموذجه، بما بحقق هيمنته الكاملة علي باقي العالم، خاصة أن مجمل هذه الحركات بسعي إلي الوصول إلي السلطة لإقامة (الدولة الإسلامية) وفي الواقع لا يفرق الباحثون الغربيون بين الحركات الإسلامية التي

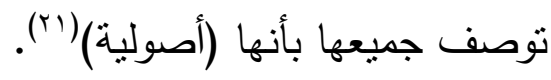

19 انظر : أوليفية روا ـ تجربة الإسلام السياسي ـ ترجمة نصير مروة ـ طץ (دار الساقي: بيروت)

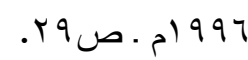
• ب انظر : واصف شديد، وسجورد فان ـ الصورة السلبية للإِسلام والمسلمين في الغرب ـ مجلة

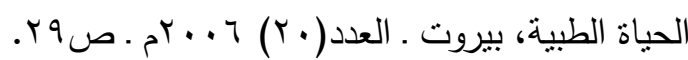

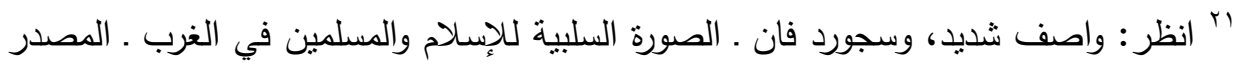

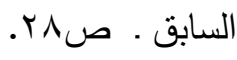




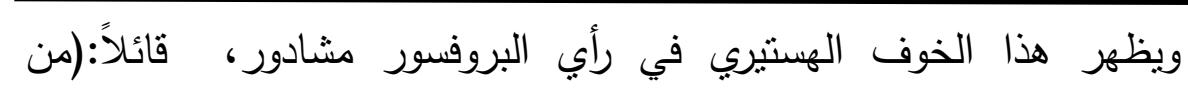
يدري؟! رُبَّما يعود اليوم الذي تصبح فيه بلاد الغرب مُهددة بالمسلمين، يهبطون

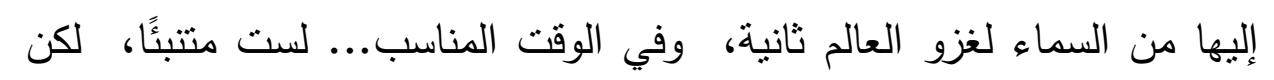

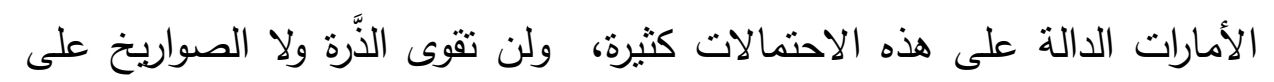

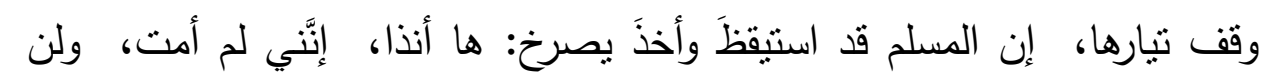

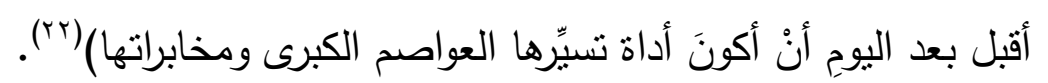

كما يعبر المستشرق الفرنسي كيمون في كتابه (باثولوجيه الإسلام)، فيقول:

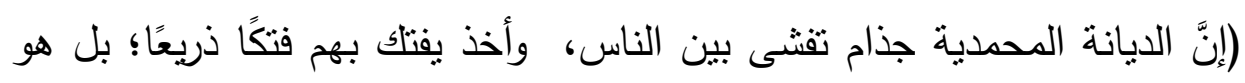
مرض مربع، وشلل عام، وجنون ذهولي، يبعث الإنسان على الخمول والكسل، ولا يوقظه من الخمول والكسل إلاَّ ليدفعه إلى سفك الدِّماء والإدمان على دهى معاقرة

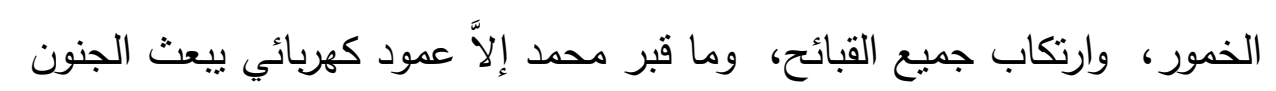
في رُؤوس المسلمين، فيأنون بمظاهر الصَّرع، والذهول العقلي إلى ما لا نهاية، وبعتادون على عادات تتقلب إلى طباع أصيلة، ككراهية لحم الخنزير والخمر

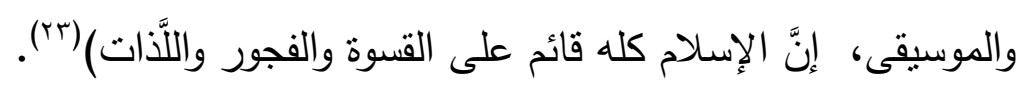
عليه يمكن القول إن إحدى مشكلات عداء الغرب التاريخي للنبي صلّى الله عليه وسلم، هو أنه جاء بنظام سياسي وفكري منكامل ينازع الغرب في المسلمات الأساسية، وكذلك في طرق التتظيم والإدارة وسياسة المجتمعات، وأخيرا في نمط العلاقات الاجتماعية داخل المجتمع، وبين المجتمعات المختلفة. إنه ببساطة نظام متكامل مواز للنظام الغربي، ولا يلتقي معه، وإنما يقدم بديلا قويا وخطيرا له.

r r محد البهي . الفكر الإسلامي الحديث وصلته بالاستعمار الغربي (دار الفكر - بيروت) (19R

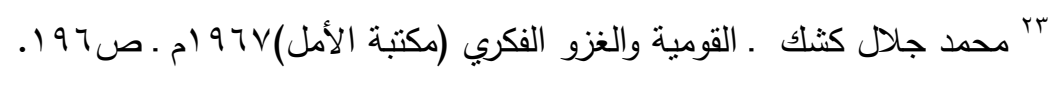
TrE 
وكما يذكر أحد المفكرين العرب فإن الخوف من قوة الإسلام المحركة يأخذ في اللحظات التراجيدية شكل الدفاع والصراع والمشاجرة، أحد أكثر الأشكال الانفعالية في التاربخ. لقد أبرز مفهوم الإسلام السياسي كتهديد متواتر، ومفهوم الدين السياسي كبنية تاريخية في أصول الإسلام. يقول غولديسهر : (إن الإسلام قد جعل الدين دنيويا لقد أراد أن يا يبنى حكما لهذا العالم بوسائل هذا العالم)(عَّ). لذلك هاجم المفكرون الغربيون بشدة المشروع الحضاري الإسلامي، واعتبروه خطيرا كبيرا يهدد سيادة الفكر الغربي وانتصار الحضارة الغربية، ونهاية التاريخ.

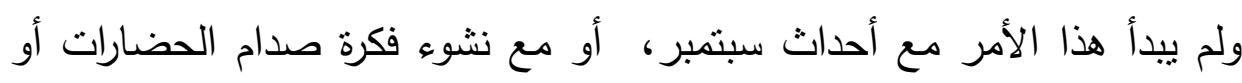
نظرية نهاية التاريخ، وإنما سبق ذلك بقرون عديدة، واستمر يغذى الثخصية الغربية بمبررات العداء للعالم الإسلامي ولشخصية النبي محمد صلّى الله عليه وسلم.

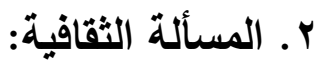

يشخل البعد الثقافي في مكانة محورية في العلاقة بين الغرب والعالم الإسلامي، وهو ما يبتدي من خلال الصور السائدة لدي كل طرف عن الآخر، والكيفية التي يشكل بها كل طرف الآخر ويرسمه من خلالها، ولعل أبرز ما يمكن استاعاؤه هنا مقولتان ذاع صيتهما في السنوات الأخيرة، هما:أطروحة فوكو ياما عن نهاية التاريخ والتي يري فيها أن النموذج الرأسمالي الليبرالي هو أرقي ما يمكن أن تصل إليه البشرية، وما علي باقي العالم إلا الانضمام إليه، ومقولة هنتنغتون عن صدام الحضارات والتي يري فيها أن صراع الحضارات سيكون المصدر الرئيس للنزاعات في النظام العالمي الجديد، وسيكون هذا الصراع مقتصراً علي الثقافة الغربية دن جهة، والثقافنين الإسلامية والكونفوشيوسية (في الصين وكوريا)

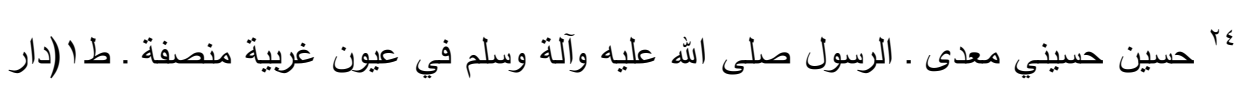

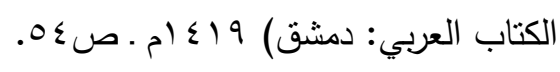




\section{مجلة معالم الدعوة الإسلامية المحكمة - العدد (السابع) - ذو الحجة بسـع اهـ/ ديسمبر ع ا ـ rم}

من جهة أخري وعلي هذا فإن تلكما الثقافتين تشكلان خطراً علي الثقافة الغربية

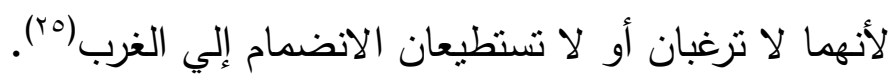

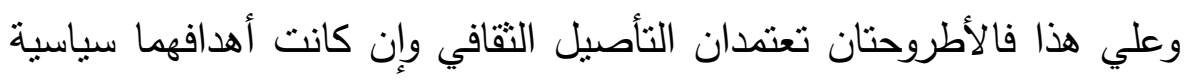

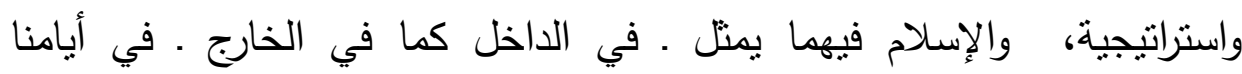

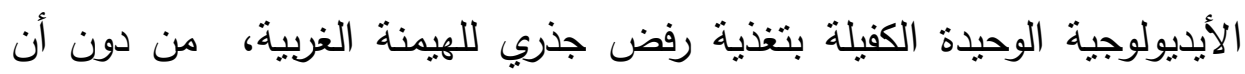

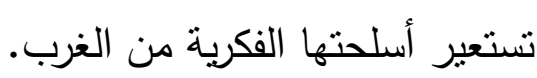

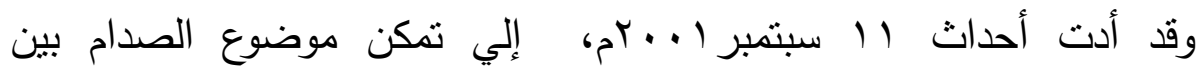

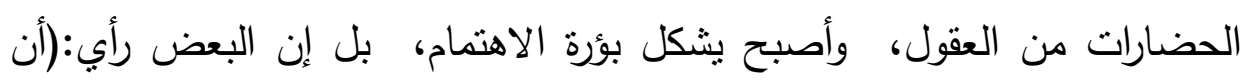

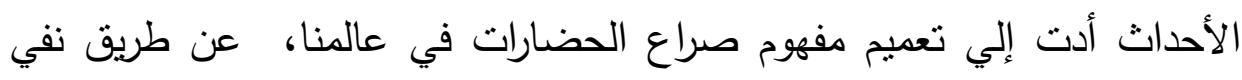

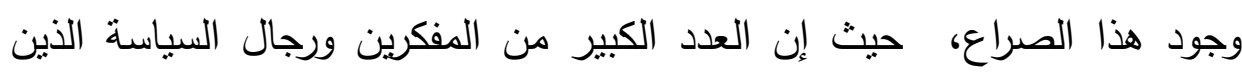

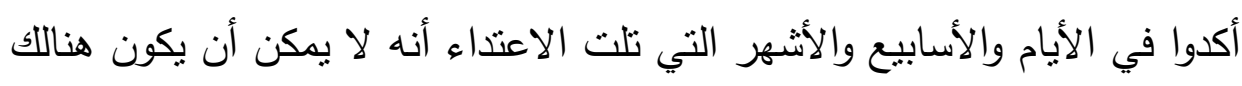

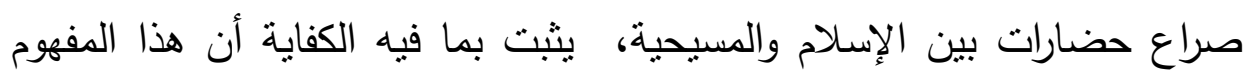

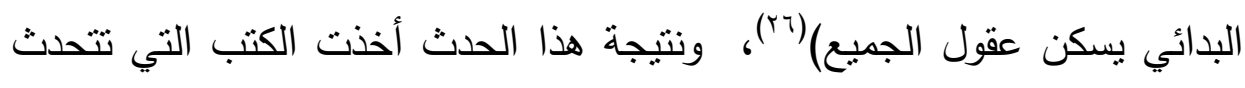

$$
\text { عن صراع حضاري حيز وسط الغربيين وروج لها. }
$$

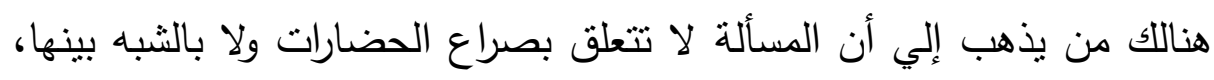

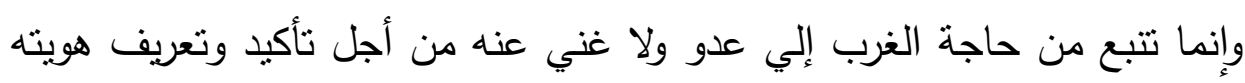

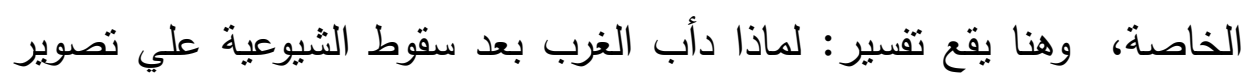

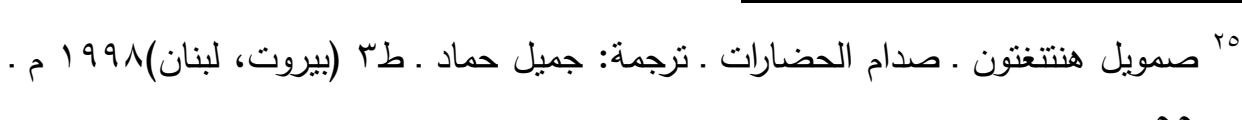

"r إيمانويل تود ـ ما بعد الإمبراطورية: دراسة في تفكلك النظام الأمريكي . ترجمة محمد زكريا

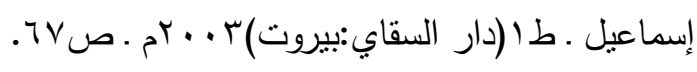


الخطر الأخضر الإسلامي بديلاً عن الخطر الأحمر لكن هاليداي وآخرين يرفضون هذا التقسير ويعتبرونه خرافة(rV).

عليه بمكن القول بأننا إذا قمنا بمراجعةً تاريخيَّة للفكر الغربي الحقيقي الذي رلي

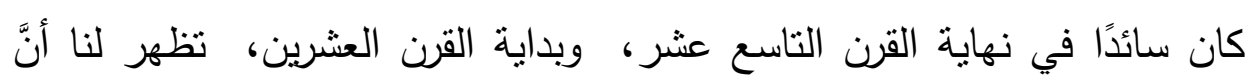
بعض الكتاب الكبار كانوا يتحدَّفن عن الإسلام، والمسلمين، ونبي الإسلام، بكل تقدير واحترام، وفخر واعتزاز ، فثنلاً نجد كاتبًا كبيرًا منل توماس كارليل الذي يعتبر أكبر عقليَّة إنجليزية بعد شكسبير يضع الرَّسول الكريم وسيرته في كتابه (الأبطال)، ويصفه بأعظم الأوصاف العظيمة، يقول عنه: (لا شيء أكبر

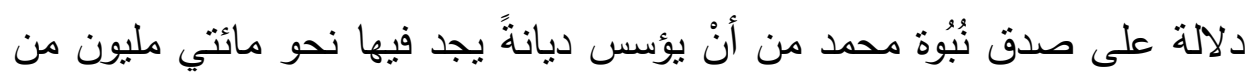
الأنفس غذاءهم الرُوحي، وتقاوم عوامل التحليل في مدى أكثر من اثتي عثر

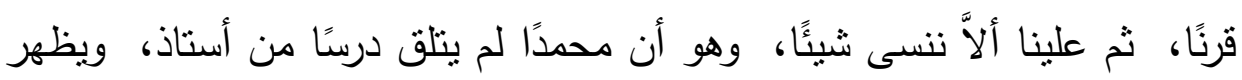

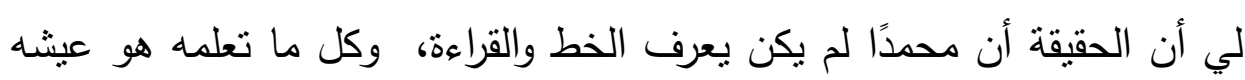

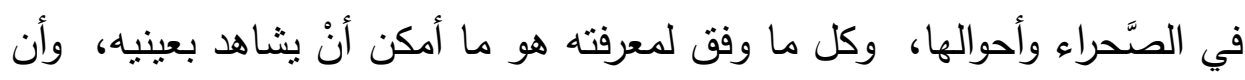

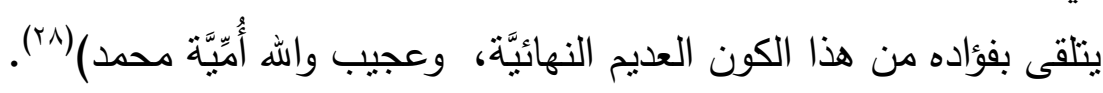
كذلك نجد الكاتب الأمريكي الكبير مايكل هارت أستاذ الرياضيات والفيزياء

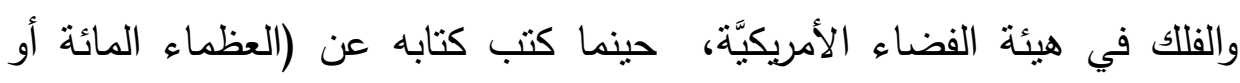
الخالدون المائة) - يجعل الرسول الكريم في مُقدمة كتابه، ويمدحه مدحًا مناسبًا، كأعظم رجل في النَّاريخ، وبقول عنه:(لقد اخترت محمدًا في أول هذه القائمة، ولا بد أنْ يدهش كثثرون لهذا الاختيار، ومعهم حق في ذلك؛ ولكنَّ محمًا هو هوه

V انظر : معتز الخطيب ـ الغضب الإسلامي ! تفكيك العنف...دراسة نقدية ـ مرجع سابق . ص $9 v$. ^ץ انظر : محمد الصادق عرجون . محمد رسول الله - صلى الله عليه وسلم - طا (دار القلم:

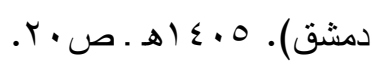
TrV 
الإنسان الوحيد في التاريخ الذي نجح نجاحًا مطلقًا على المستوى الديني والدنبوي، وهو قد دعا إلى الإسلام ونشره، كواحد من أعظم الدِّانات، وأصبح قائدًا سياسيَّا وعسكريًا ودينيَّا، وبعد ثنلاتثة عشر قرنًا من وفاته، فإنَّ أثز محمدٍ ما يزال قويَّا

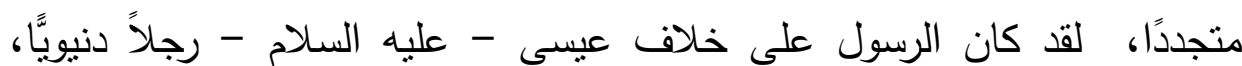
فكان زوجًا وأبًا، وكان يعمل في التجارة، ويرَرعى الغنم، وكان يُحارب ويُصـاب في الحروب ويَمرض، ولما كان الرسول ثُوَّة جبارة، فيمكن أنْ يقالَ أيضًا: إنَّه أعظم سياسي عرفه التاريخ - ويضيف: فهذا الامتزاج بين الدين والدنيا هو الذي هي

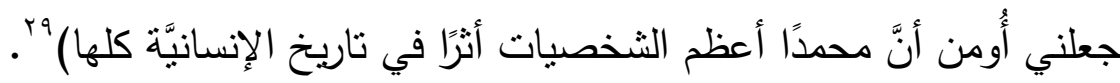
إذا أردنا أن نعرف شيئاً بسيطاً من عظمة النبي صنلَّى اللهُ عَلَيْهِهِ وَسَلَّمَ وأثره في واقع هذه الدنيا وفي حياة الإنستانية جمعاء ؛ فلنظظر إِلَى واقع الأمم التي بُعث

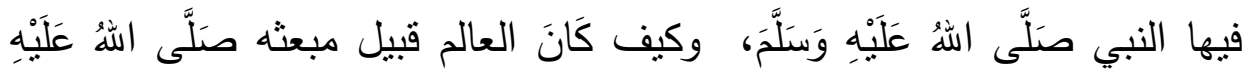
وَسَلَّمَ، إنَ أي مؤرخ مُنصف يقرأ وينتبع حال العالم قبل بعثته صَلَّى اللهُ عَلَيْهِ

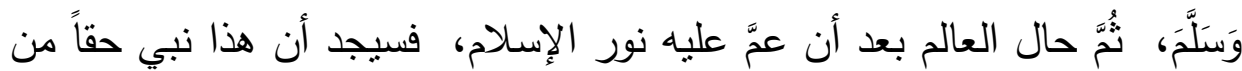

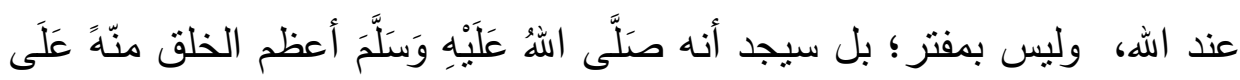
البشر، وعلى الإنستانية جمعاء، وعلى سائر الحضارات.

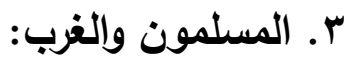

إذا رجعنا إلي الخلفية التاريخية التي تحكم العلاقات بين العالم الإسلامي والغرب، نجدها مبنية علي كراهية الآخر ولها أسبابها. فمن العوامل المؤثرة في كراهية الإسلام تزايد هجرة المسلمين إلي الغرب، خاصة خلا الستينيات من القرن العشرين والتي أثارت نقاشات اقتصادية واجتماعية في بداية الأمر، لكن منذ بداية الثمانينيات . بعد الثورة الإسلامية الإيرانية ـ أخذ الإعلام يربط بين تلك النقاشات وبين ثقافة وديانة هؤلاء المهاجرين، بله بله 
فبرز النقاش حول ما إذا كانت قيم وثقافة هؤلاء تتسجم مع التقافة الغربية، وفي هذا السياق تبرز مسائل عديدة من قبيل الحجاب وتعدد الزوجات وختان الإناث وإنشاء مدارس إسلامية إلي غير ذلك، بل إن الأمر لاحقاً تجاوز نلاك النقاشات إلي مسائل الولاء والمواطنة ومدي نأثير الحركات الإسلامية في العالم الإسلامي علي المسلمين داخل الاتحاد الأوربي، ثم جاءت أحداث سبتمبر فأدت إلي طرح مسألة الولاء للوطن بقوة، بل إن هنتختون قدم أطروحته الثانية عما أسماه الهوية (الهوية الأمريكية) التي يجب الحفاظ عليها، والتي تقوم علي ركائز أربع أساسية، هي العرق الأبيض، والأثتية الإنجليزية والدين المسيحي البروتستانتي، والثقافة الإنجليزية البروتستانتية(·r).

إن موقف الغرب السلبي من المهاجرين المسلمين في أوربا يعود لسببين: أحدهما: هو الأهم الاختلاف العرقي، والعداء المتصاعد للمسلمين هناك يعود لرفض مجموعات معينة تقبل حقيقة أن مختلف بلدان أوربا الغربية أصبحت دول هجرة، ومن ثم تخشي أن تفقد الإطار التقافي في ظل التعددية التقافية التي تتفاعل داخلها ونشأة التمايزات، والسبب الثاني: لتدهور الموقف الغربي من المسلمين يمكن أن يعزي لتحريف إحصائي كما في بلدان أوربا حيث ظهر تزايد علماني ونزايد عدد المسلمين أيضاً، ويتتاقص عدد أعضاء الكنيسة، وهذا يزبد

$$
\text { من مخاوف الأسلمة في الغرب(بان. }
$$

وكان فريد هالبداي خصص فصلاً كاملاً لعداء الغرب للمسلمين رافضاً مقولة الإسلاموفوبيا والتي تعني خوف أو عداء الغربيين للإسلام، هو يري أنه ليس

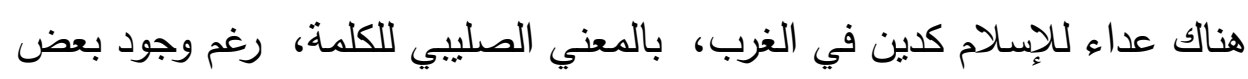

Samuel p. Huntingtonk, who Are we: The Challences to Americas . Natioal Identity, New york: Simon Schuster $r$. . $s$

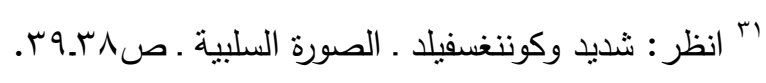


تسريبات الإرث التاريخي والتصورات المتوارثة، لكن الأهم والسائد في رأيه هو موجات العداء للمسلمين كناس وليس للإسلام كدين ونظرية، وهو عداء ذو جذر سياسي واجتماعي وليس ثقافياً دينياً، وأغلب العداء مرتبط بالمهاجرين والظروف وهن الاقتصادية، وإلي حد ما هناللك الجهل والتجهيل الذي أثارته نظرية(الإسلام الخطر البديل عن الثيوعية) بحسب رأي هاليدي(rم).

وإذا ما حاولنا أنْ نفهَ بعضَ تحليلاتِهم لأسباب خوفهم من الإسلام عَبْرَ تحليلهم للإسـام المخيف، وجدنا ذلك في قول مسئول في وزارة الخارجيَّة الفرنسية عام 90 ام ؛ حيث يقول:(ليست الثيوعية خطرًا على أوروبا فيما يبدو لي، إنَّ

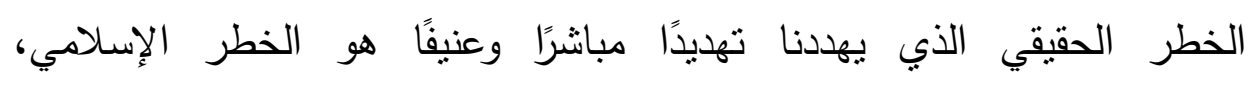
فالمسلمون عالم مستقل كل الاستقال عن عالمنا الغربي، فهم يمتلكون ثراثَهْ

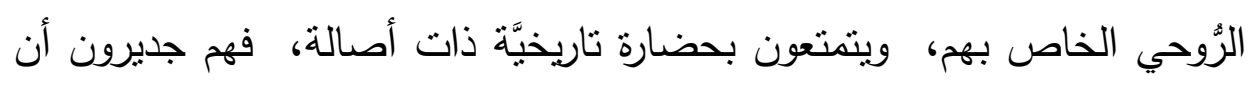
يقيموا قواعدَ عالم جديد، دون حاجة إلى إذابة شخصيَّتهم الحضارية والرُّوحية في

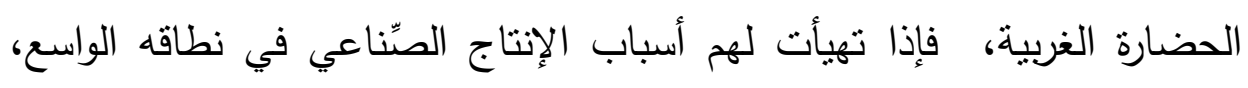

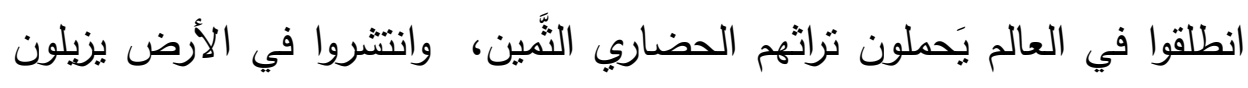
منها قواعد الحضارة الغربية، ويقذفون برسالتها إلى متاحف التَّربخ، وقدي حاولنا

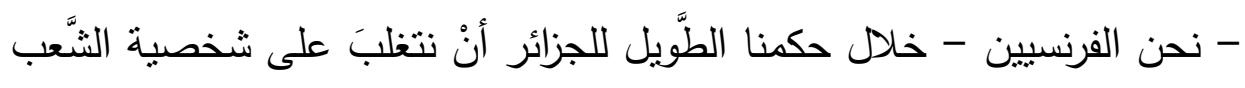
المسلمة، فكان الإخفاق الكامل نتيجة مجهوداتتا الكبيرة الضَّخمة.إن العالم

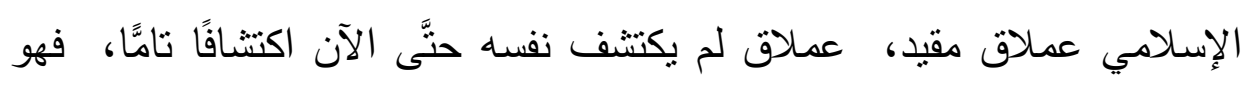
حائر، وهو قلق، وهو كاره لانحطاطه وتخلفه، وراغب رغبة يُخالطها الكسل

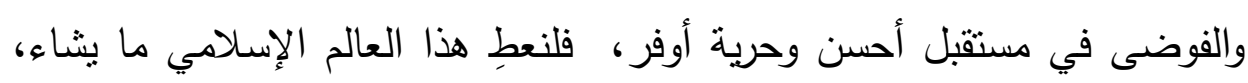

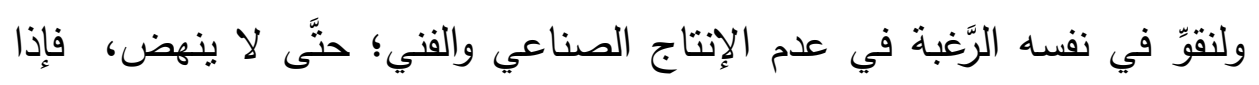

بr فريد هاليداي ـ ترجمة عبد الإله النعيمي · ساعتان هزتا العالم: (11 أيلول) - طا(دار

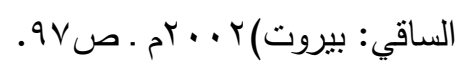
. 
عجزنا عن تحقيق هذا الهدف بإبقاء المسلم متخلفًا، وتحرر العملاق من قيود

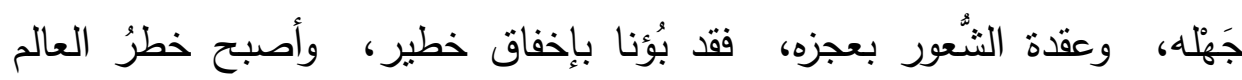

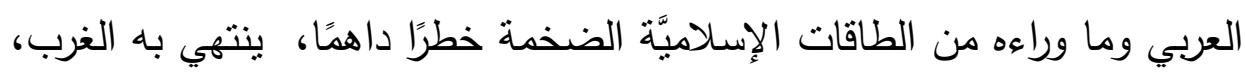

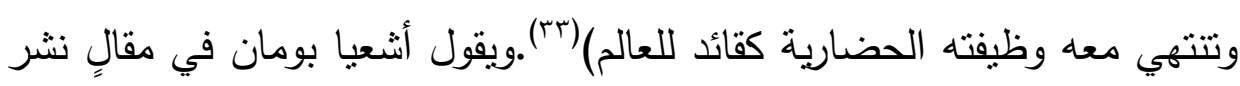
في مجلة الإسلامي التبشيرية:(إن شيئًا من الخوف يجب أن يسيطرَ على العالم الغربي من الإسلام؛ لهذا الخوف أسباب؛ منها أنَّ الإسلامَ منذ ظهر في مكة لم يضعف عدديًّا، بل أتباعه يزيدون، ومن أسباب الخوف أنَّ هذا الدين من أركانه

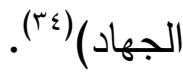

عليهم أن يعلموا بأنه لا بد أن يأتي اليوم إن شاء الله الذي يرفع فيه جميع الحواجز التي وضعها المرجفون الجاهلون والكافرون الجاحدون لقمع انتشار الإسلام دين الهدى والحق، وإن لا سعادة إلا في الإسلام، وقيمه الأصيلة، وعقيدته الصافية، وشربعته العادلة. وما زالت الدنيا مفتوحة بقدر للعلماء العاملين، والدعاة المخلصين الذين يبلغونه بالحكمة والموعظة الحسنة والقدوة الحسنة، وعليهم أن يعلموا أن اله غالب على أمره، ولكن أكثر الناس لا بعلمون ،وأن من كتبت له الهداية لابد له أن يهتدي مهما كانت العوائق والعقبات.

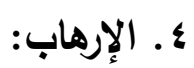

بعد الرجوع إلي كتب اللغة العربية لمعرفة معني لفظ إرهاب وجدنا هذا اللفظ

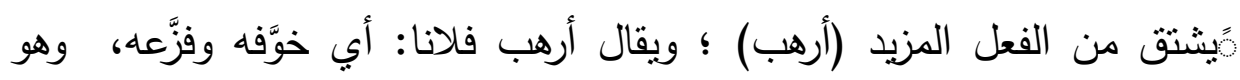
المعنى نفسه الذي يدل عليه الفعل المضعف (رَهّبَ). أما الفعل المجرد من المادة نفسها وهو (رَهِبَ)، يَرْهبُ رَهْبَةً ورَهْبًا ورَهباً فيعني خاف، فيقال: رَهِبَ الثَيء

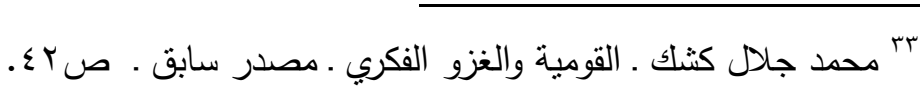

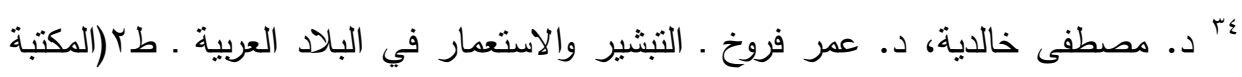

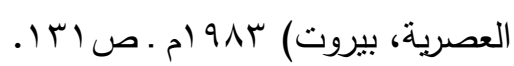


رهبا ورهبة أي خافه. والرهبة: الخوف والفزع. أما الفعل المزيد بالتاء وهو (تَرَهَبَ) فيعني انقطع للعبادة في صومعته، ويشتق منه الراهب والراهبة والرهبنة والرهبانية،

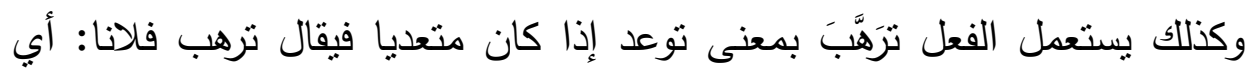

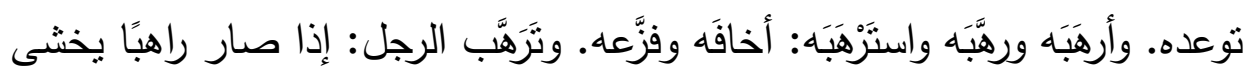

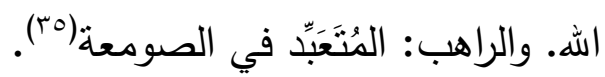

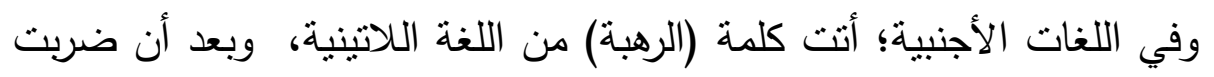

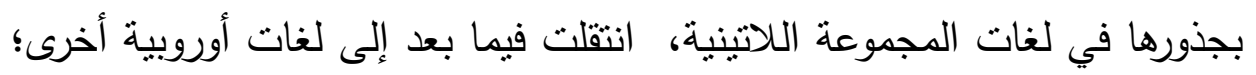

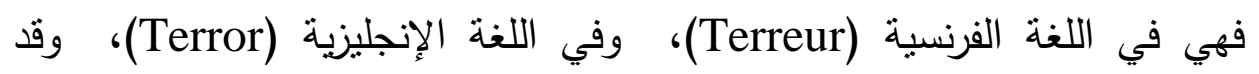
عرّفها (قاموس المورد) بمعان تتدرج في ثلاث مجموعات: الأولى: نتظظم المعاني

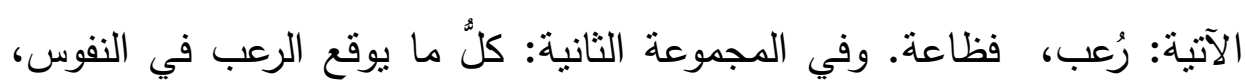
ومظهر رهيب، ومصدر قلق، وشخص أو شيء مروع، وبخاصة طفل مزعج.

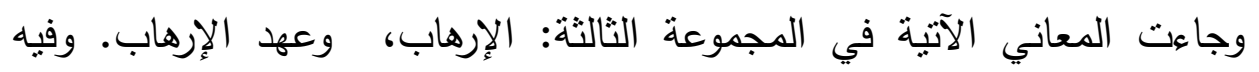
أيضاً: (Terrorism) إرهاب، ذَعر نابشئ عن الإرهاب. وكذلك: (Terrorist)

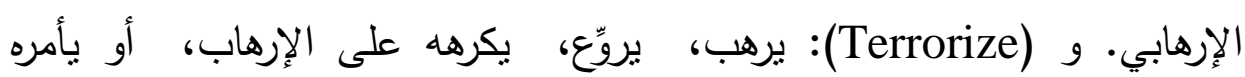
باه (זr).

وأما تعريف الإرهاب في الاصطلاح ليس هناك حتى الآن تعريف واضح له،

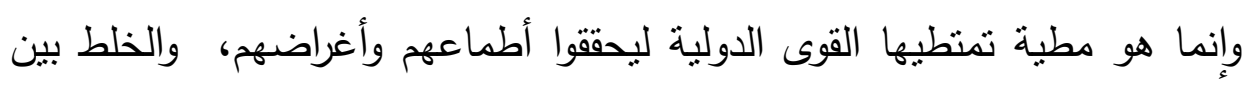

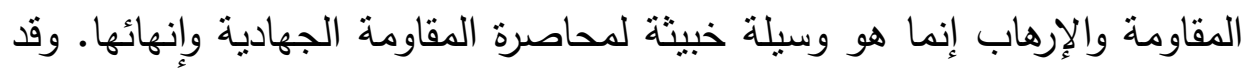

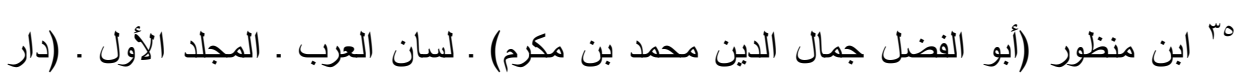

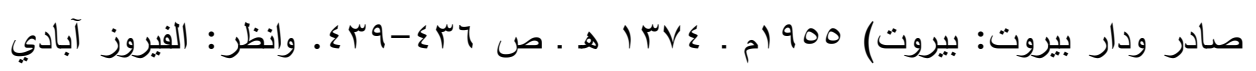

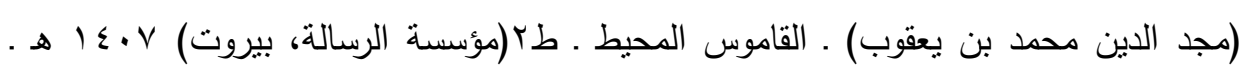

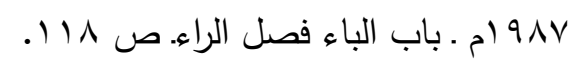

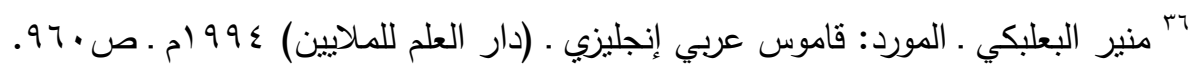
rrr 


\section{مجلة معالم الدعوة الإسلامية المحكمة - العدد (السابع) - ذو الحجة ب ع اهـ/ ديسمبر \& ا ـrم}

صدر في تحديده بيان عن مجمع الفقه الإسلامي في رابطة العالم الإسلامي بمكة

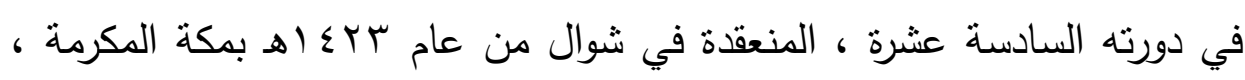

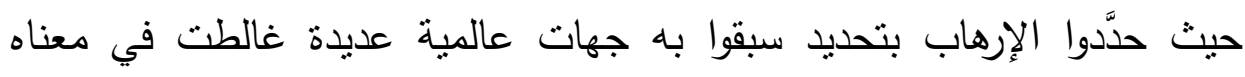

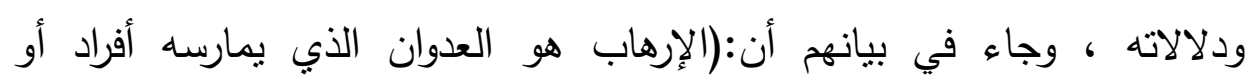

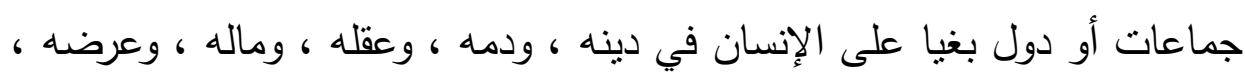

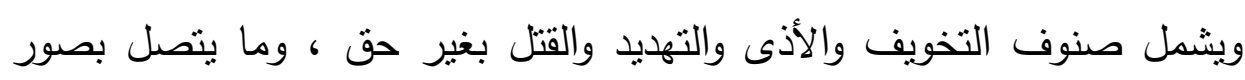

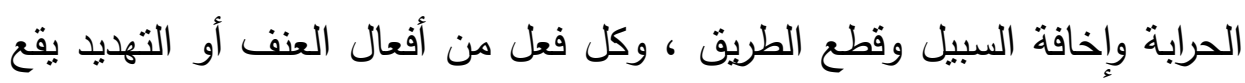

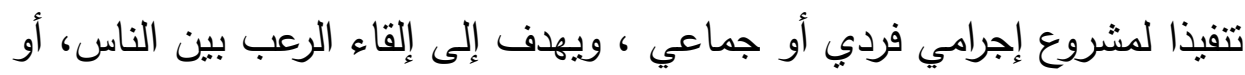

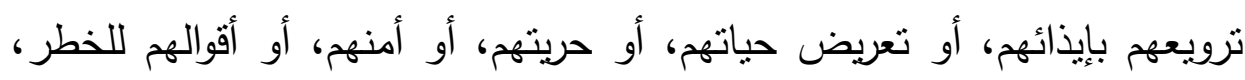

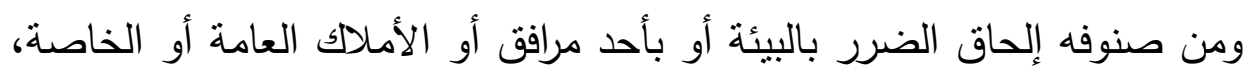

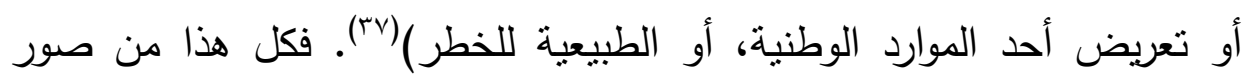

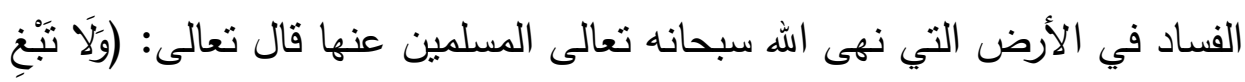

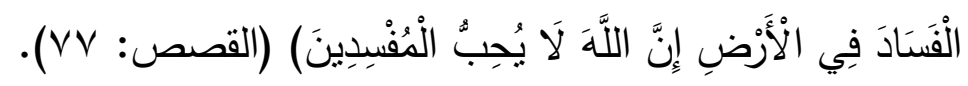

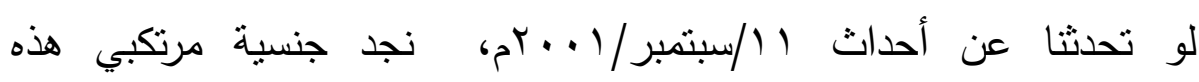
التقجيرات المفترضين استتهضت المخزون النقافي والصورة النمطية للإسلام

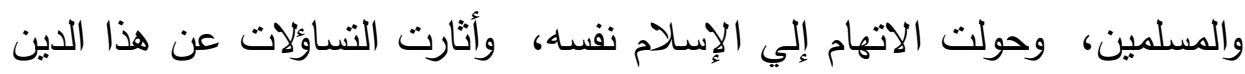

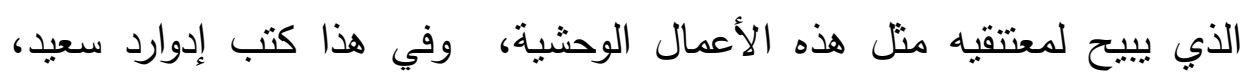

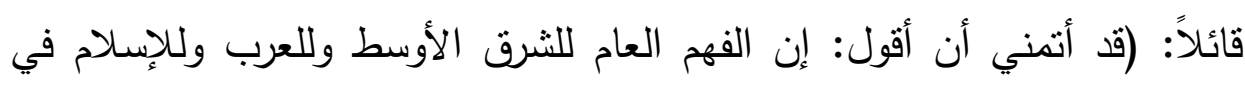

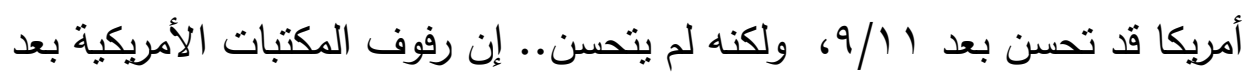

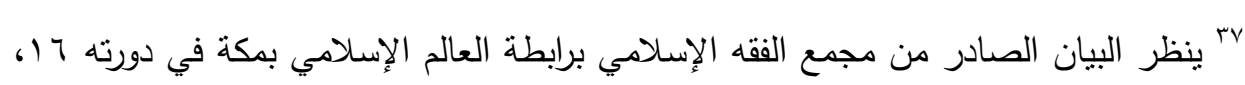

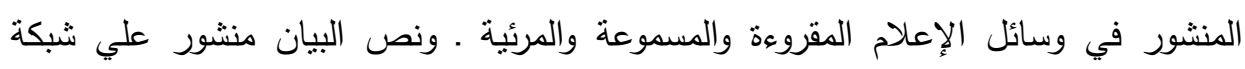

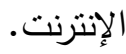


ا/ /سبتمبر امتلأت بكتب مليئة بعناوين مهلهلة صارخة عن الإسلام والإرهاب

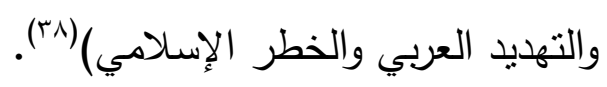

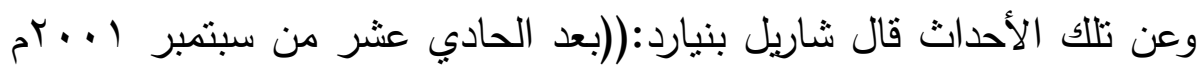
مباشرةً بدأ السياسيون وصناع القرار في الغرب بالإدلاء بتصريحات نؤكد قناعتهر

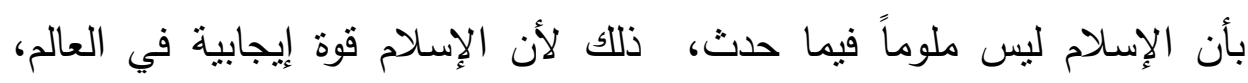
وكان ديناً للسلام والتسامح، هيث تحدثوا في المساجد وعقدوا اجتماعات واسعة مع علماء مسلمين، وقاموا بدعوة الثخصيات الدينية الإسلامية البارزة في افتتاح

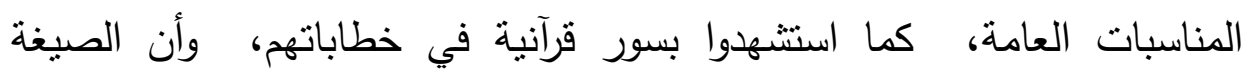
النموذجية لهذا الخطاب الذي يبرئ ساحة الإسلام: خطاب بوش r · . rم الذي قال فيه:(إن الإسلام دين يوفر الرفاهية لمليار من البشر حول العالم...لقد آخي الإسلام بين مختلف الأعراق فهو دين قائم علي الحب لا علي الكراهية)..إن هذا النهج لم يكن قاصراً علي الولايات المتحدة بل كان سائداً في أوربا أيضاً، وقد وقد انضم المجتمع الأكاديمي بسرعة إلي هذه الجهود)(ب(ra).

لكن لا يمكن تجاهل مواقف بعض قيادات اليمين الأمريكي المتدين تجاه الإسلام، والتي قال عنها ديفيد فروم ـ أحد كتاب خطابات بوش سابقاً: (إن قيادات اليمين الأمريكي المتدين، الذين يمثلون أقوي القواعد الجماهيرية المساندة لبوش، شعروا بغضب شديد تجاه موقف بوش من الإسلام والمسلمين في أعقاب أحداث سبتمبر لأن بوش وصف الإسلام بأنه دين سلام)(•؛)، وتقول جويس ديفس:((إن

^r الكلام جزء من مقدمته الجديدة لكتاب الاستشراق . التي نشرتها الجارديان بتاريخ . $r \cdot T / \Lambda / r$ 9َّ شاريل بنيارد ـ الإسلام الديمقراطي المدني:الثركاء والمصادر والاستراتيجيات ـ (مؤسسة رائد)

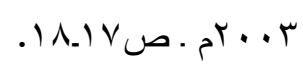
•ديفيد فيروم ـ الرجل المناسب: الرئاسة المفاجئة لجورج دبليو بوش ـ r . . بم. 
كلاً من صناع القرار والمواطنين الأمريكيين العاديين لديهم صورة مشوهة عن الإسـام والعالم الإسلامي، وإنه لمن الصعب تغيير هذه الصورة النمطية السلبية، ومن الأصعب تجسير هذه الفجوة المعرفية بين الغرب والإسلام، خصوصاً أن

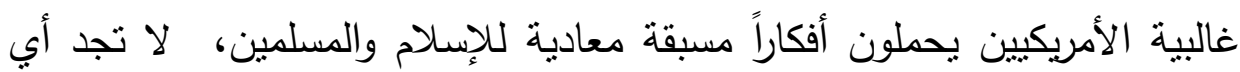
أساس معرفي لها، وتري أن علي الولايات المتحدة أن تحاول الحد من تكرار الصورة النمطية عن الإسلام والمسلمين التي تجعل من المسلمين إرهابيين)(اءع). الأمر نفسه يؤكده أكبر أحمد عالم الأنثروبولوجيا الذي يري أن الإسلام (تحت الحصار ) وهو حصار تفرضه رؤى سياسية وإستراتيجية وإعلامية وأيديولوجيا عامة معادية للإسـام، وبصعب علي دارسي الإسلام خاصة بعد ا اسبتمبر نزعتهم الانتقائية في قراءة الإسلام، وخاصة في حقل الإعلام، ويقول:(إن خبراء الإعلام الجاهزين علي الفور، كهم مذنبون في منل هذا الاستخدام الانتقائي للإسلام عموماً وللقرآن الكريم لتدعيم وجهات نظرهم الجاهزة)(ז٪)، ويؤكد كذلك علي أن أن الرؤية العامة للإسلام تتسم برؤية تبسيطية تحصر الإسلام في العنف والإرهاب بل إن الأنثروبولوجي إيمانويل تود، قال:(إن الإسلام المحافظ شُفر بالغة الدارجة بمفهوم الإرهاب الذي يرغب كثيرون في أن يروه شاملاً جميع العالم)(َّ). ومما بزيد الإرهاب استشراء ويعمق الخلاف الخلط بين الإرهاب والمقاومة، فكفاح الثعوب من أجل تحرير نفسها من السبطرة أو التخخل الأجنبي عمل الإهل ا؛ أحمد يوسف ـ مستقبل الإسلام السياسي: وجهات نظر أمريكية . طا (المركز الثقافي العربي:

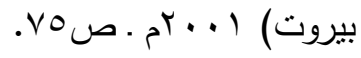

rأ ايمانويل نود؛ ترجمة محمد زكريا إسماعيل ـ ما بعد الإمبراطورية: دراسة في تقكك النظام

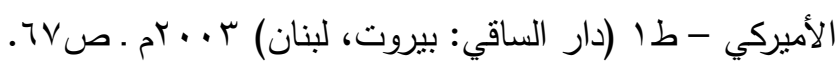

rأ انظر : إدوارد سعيد ـ تغطية الإسلام: كيف تتحكم أجهزة الإعلام ويتحكم الخبراء في رؤيتتا

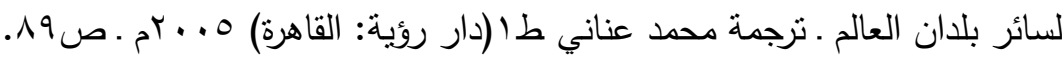




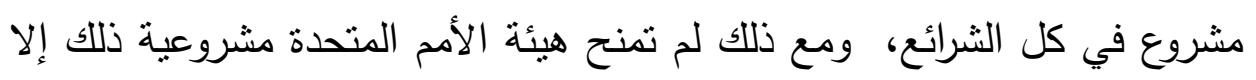

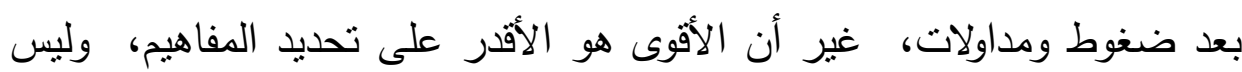

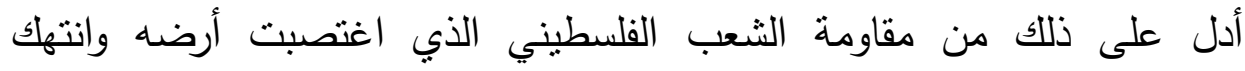
عرضه، وسال دمه فنجد الاستتكار من قبل الإعلام الغربي وينظر إلي انتهاكات

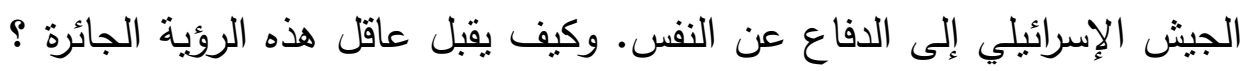

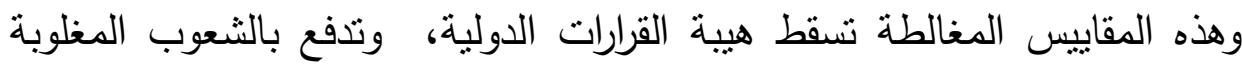

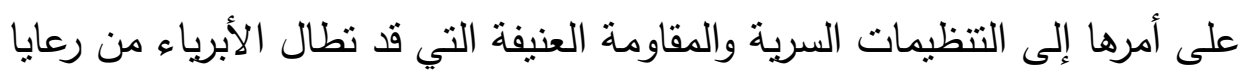
الدول المتواطئة مع الظلم والراعية له.

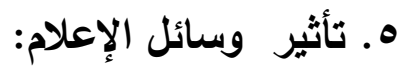

دور وسائل الإعلام الغربي:الإعلام الغربي بتقنياته الهائلة وتأثيره الواسع من

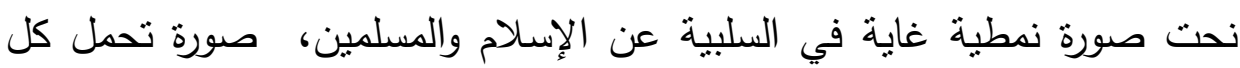

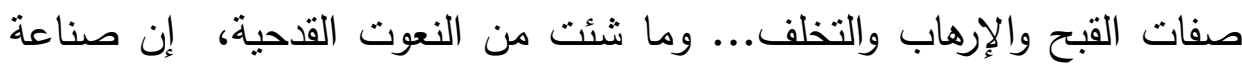

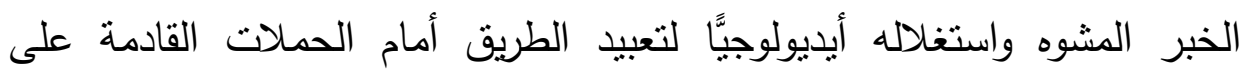

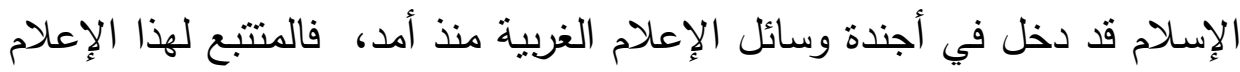

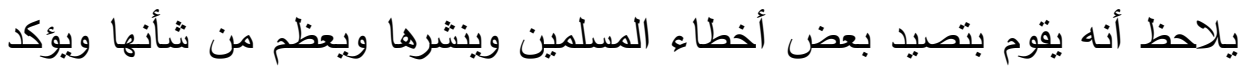
أن هذا هو الإسلام، فجميع وسائل الإعلام وخاصة الإعلام السينمائي المرئي لئي

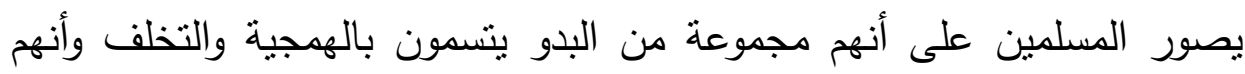

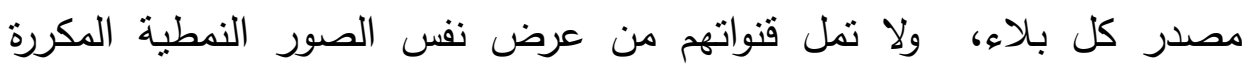

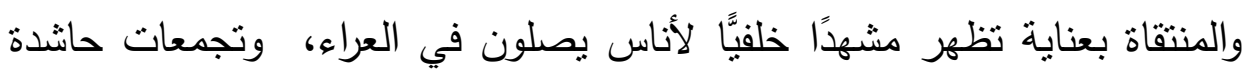
تولول وتهدد، ونساء منقبات، و ووجوه ملتحية، وأفواه مفتوحة وعيون محلقة.

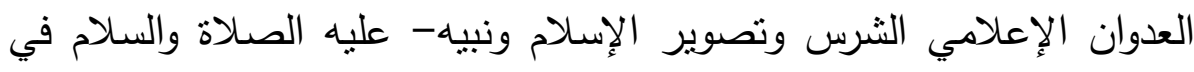

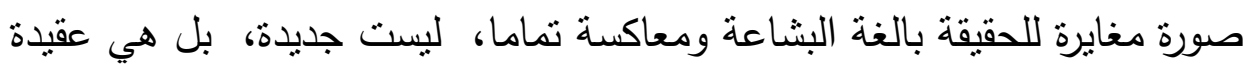
غربية موروثة تتكلت ونمت خلال ثمانية قرون منذ القرن الأول وحتى نهاية القرن 
الثامن الهجري. قد يظن كثير من المسلمين أن العدوان الغربي على الإسلام

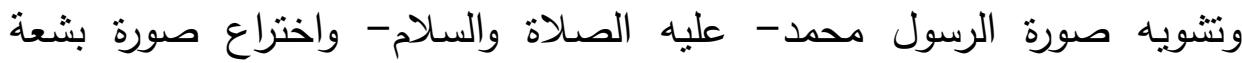
ومعاكسة لحقيقة دين الإسلام ونبيه من طرف وسائل الإعلام في الغرب، لاسيما

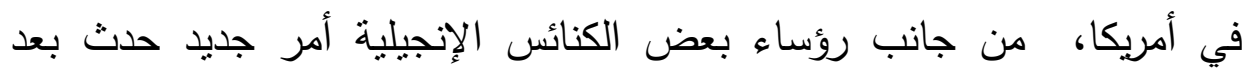

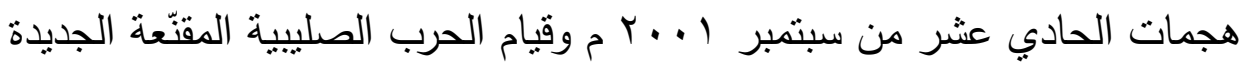
التي تقودها الولايات المتحدة ضد الإسلام والمسلمين تحت قناع (الحرب على

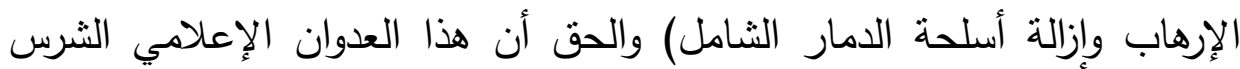

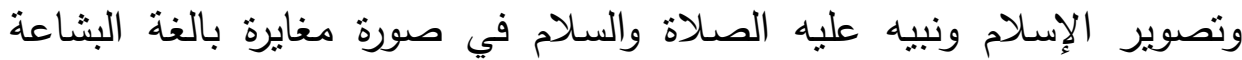
ومعاكسة تماما، ليست جديدة، بل هي: عقيدة غربية موروثة تثكلت ونمت اليتام خلال ثمانية قرون منذ القرن الأول وحتى نهاية القرن الثامن الهجري. وانتقلت هذها العقيدة كاملة متماسكة عبر القرون لتصل إلى القرون الحديثة والمعاصرة. وأصبحت أثنبه بالمستتقع الآسن العفن الذى تغرف منه وسائل الإعلام الغربية وبعض رجال الدين الإنجيليين في أمريكا، وينشرونها عبر وسائلهم المختلفة(؛؛).

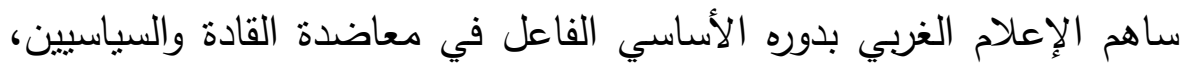

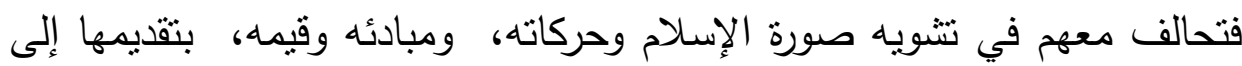

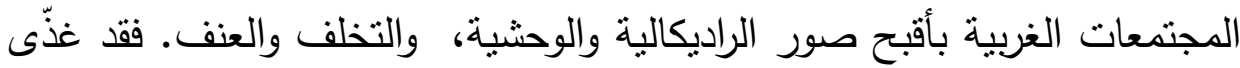

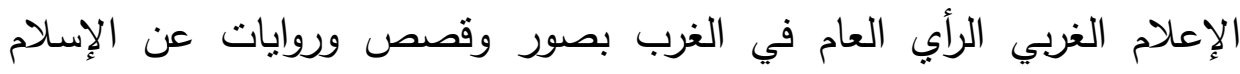
والمسلمين، أصبحت أثند من الكوابيس ضغطاً على عقل وقلب وفكر المواطن

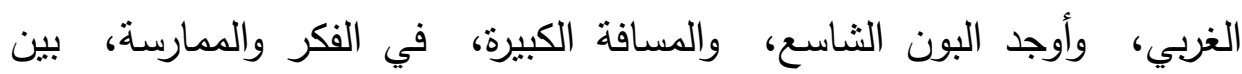

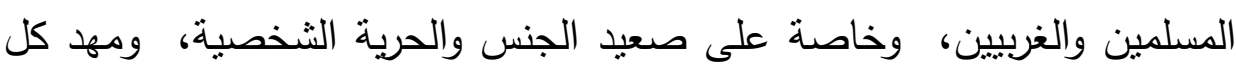

؛؛ حسين حسيني معدى . الرسول صلى الله عليه و آله وسلم في عيون غربية منصفة . صعٌ مصدر سابق. 
ذلك أمام السياسيين، مهمة التلاعب بالرأي العام الغربي وتوجيهه، وحثده خلف

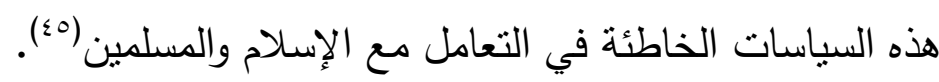
يقول المستشرق الهولندي (رودلف بيترز): (أن اللغة الإعلامية اليومية . للغرب ـ تكرس الصورة المشوهة، ويساهم في التشويه بعض الفئات المتعلمة والصحافيون. إن نقد صحافتنا أمر واجب، لأنها تمضي بعيداً في تسويق مفهوم

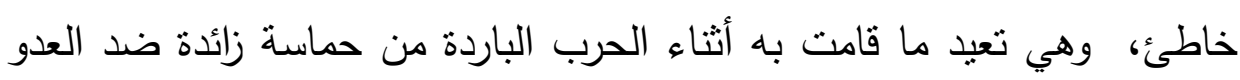

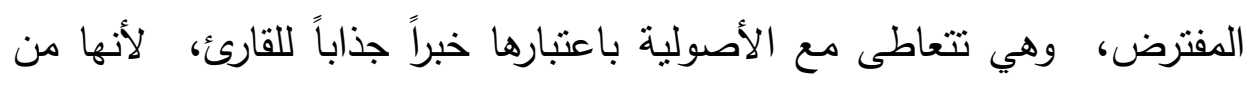
ناحية تتبنى العنف والإرهاب، ومن ناحية أخرى تختلف عن الواقع الغربي

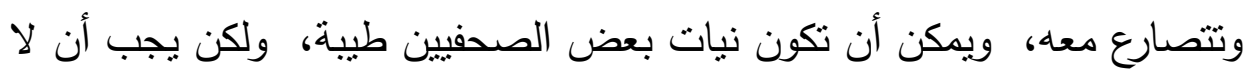
ننسى المقربين من المؤسسات السياسية الحزبية، التي لها مصلحة في التلاعب بالرأي العام وتوجيه. وحتى الصحافي الموضوعي يواجه عوائق مهنية في تغطية الموضوع الإسلامي، فرؤساء التحرير يبحثون عن خبر ، والحديث عن الإسلام

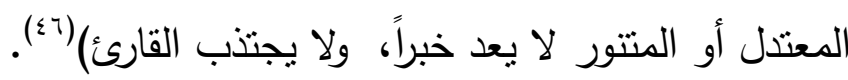
الأكاذيب الكبرى.. يتبعها ناس كثيرون.. عبارة شهيرة لهنلر تتطبق بامتياز علي ما يشهده العالم عما يقال عن إقامة تحالف دولي ضد ما يسمي (الإرهاب الإسلامي)، مما بدل علي وقوع العقل الغربي في أسر عقلية عنصرية تلفيقية

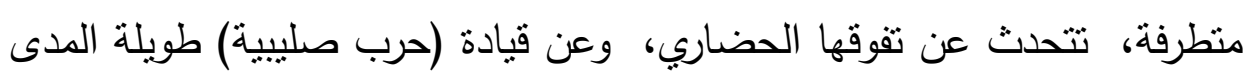
تعتمد علي إجراءات علنية وأخري سرية.. ضد الإرهاب تحت عنوان (النسر

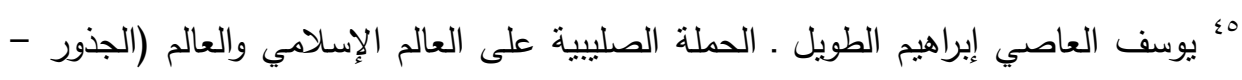

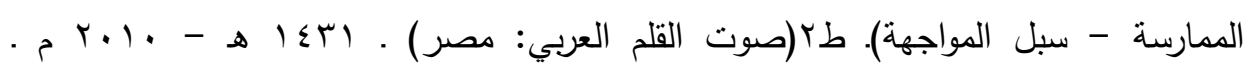
جrصو9.

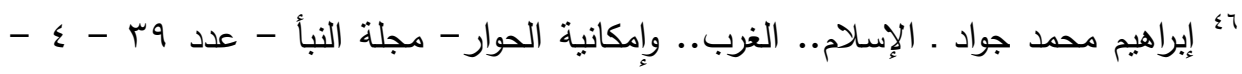

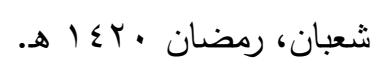


النبيل) وتتنهي (بانتصار الخير علي الثر)، لتحقيق (العدالة الأبدية المطلقة).

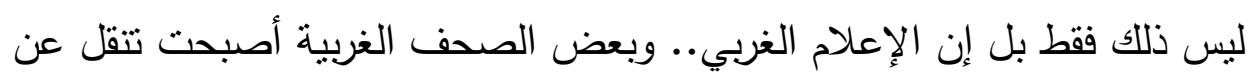

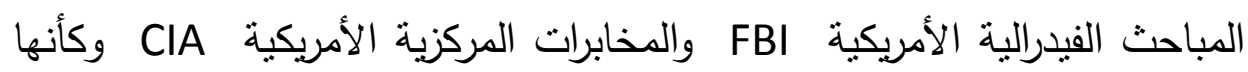

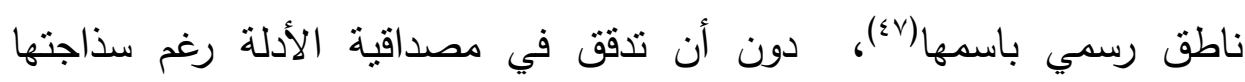

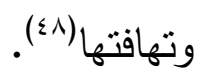

الإعلام الغربي، وهو إعلام يقوم على ترسيخ صور نمطية عن الذات

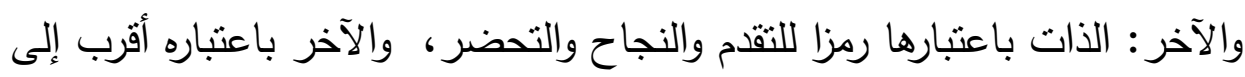

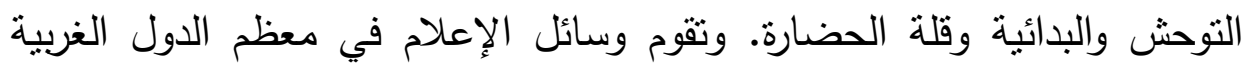

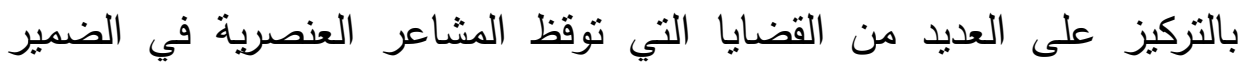

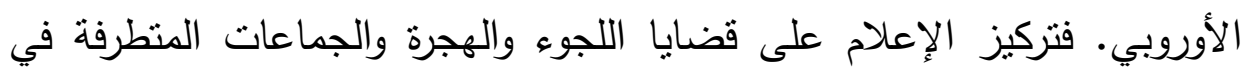

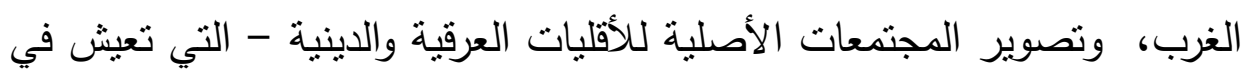

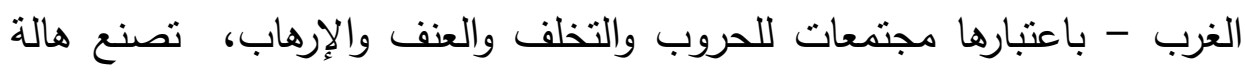

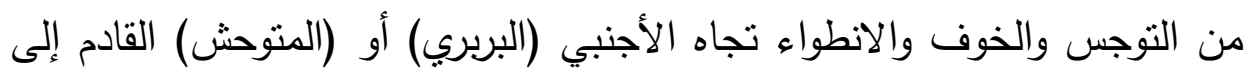
قلب الجنة الغربية من أجل إفسادها وتدميرها.

وفضلا عن تركيزها على الجوانب السلبية في حياة الأجانب والأقليات العرقية

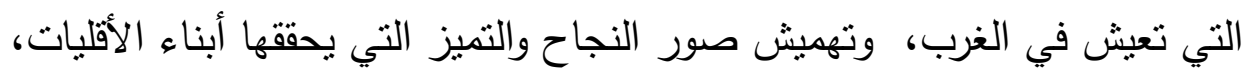

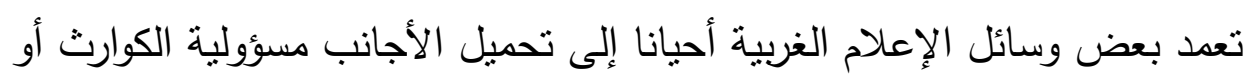

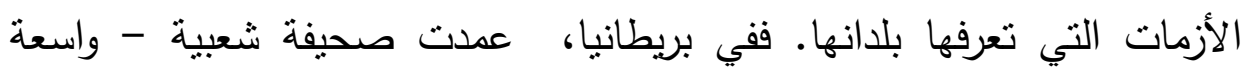

"اء لم يقتصر هذا الأمر على وسائل الإعلام الغربية، بل أن كثير من وسائل الإعلام العربية تبعتها في ذلك.

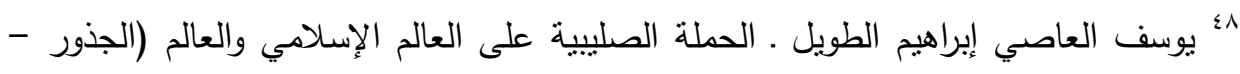

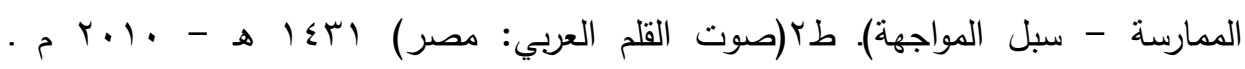
جrصع^ا. 
الانتشار - إلى تحميل الأجانب مسؤولية مرض الحمى القلاعية الذي ضرب بريطانيا، وتنبب لها في خسائر اقتصادية هائلة حين أرجعت وجود الفيروس إلى هروئ أطنان اللحوم التي قالت إنها تُهرّب من أدغال إفربقيا، وتدخل بربطانيا دون رقيب- وهي تحمل أصنافا شتى من الفيروسات والآفات(9ء). لقد أسهمت حركات التتصير ومؤسساتها الدينية في التنكيك في الإسلام والطعن في مقداته، ولا تخفى علينا كتابات كثير من المستشرقين داخل الدوائر الأكاديمية، وانتهاء بقنوات الاتصال ووسائل الإعلام المعاصرة، وكل بلمس تصعيد حملات الدعاية المناوئة للإسـلام وتشوبيه صورته أمام الرأي العالمي بشكل محموم، بعد أحداث الحادي عثر من سبتمبر ا . . Y، والتي أثعلت جذوة نيران

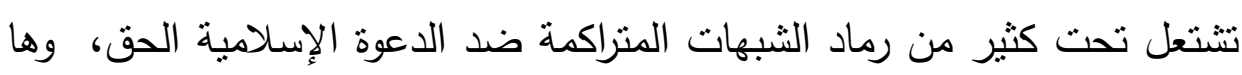
نحن نسمع كل يوم هذه الإساءات تصب على رؤوس المسلمين وليس آخرها التشويه الكاريكاتوري المسيء لرسولنا الكريم -صلى الله عليه وسلم - المنشور في صحف ومجلات دنماركية ونرويجية، فالتشويه والصمت عن محاسن الإسلام هما السلاحان الرئيسيان لبعض وسائل الإعلام الغربي في تنكيل الرعب الهستيري من الإسـام، بل بلغ الأمر التطاول على مقام سيد الخلق والمرسلين وشتمه علناً من قبل رموز دينية مسيحية وبهودية وأخرى سياسية عبر وسائل الإعلام، بل والدعوة إلى توجيه ضربة عسكرية، انتقامية أو وقائية في إطار ما يسمى بـ(الحرب على على الإرهاب)، لهدم الكعبة الثريفة وقصف مكة المكرمة بقنبلة نووية. وظهر لئه

9؛ جمع وإعداد علي بن نايف الثحود ـ الخلاصة في فقه الأقليات (1-9) ـ الباحث في القرآن

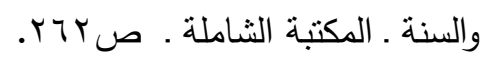
r. 
الصليبيون الجدد بشعارهم القديم والمطالبة برفع الصليب على مقدسات المسلمين

$$
\text { وأطله الحرم المكي بعد تدميره!(0.). }
$$

وتعتبر صورة العرب والمسلمين المشوهة - والمقترنة في الإعلام الغربي بكل

ما هو قبيح وسيى - أحد أبرز المظاهر على دور الإعلام والتعليم ومختلف أجهزة الثقافة الثعبية في إنتاج الكراهية والحقد على العرب والمسلمين لدى الغربيين. وهي الظاهرة التي تعرف اليوم في الدراسات الاجتماعية الغربية باسم (الإسلاموفوبيا)، أي الخوف والتخويف من الإسلام، وتصويره باعتباره بعبعا

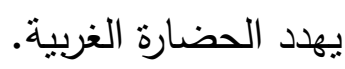

ولقد أنبأنا القرآن الكريم بهذه الحماتات التي تدق طبول الحرب بوسائل الإعلام

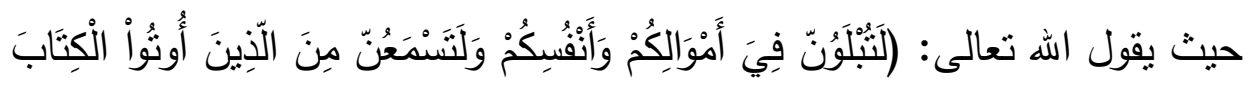

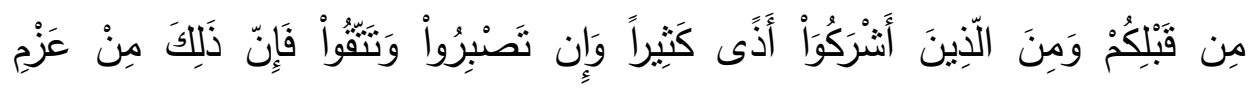

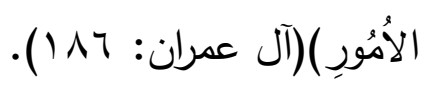

• محمد مسعد ياقوت ـ نبي الرحمة الرسالة والإنسان . طا (الزهراء للإعلام العربي: القاهرة)

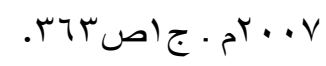




\section{الحلول للتخلص من الإسلاموفوييا}

ولتجاوز هذه الظاهرة ومعالجتها لابد من معالجة مجموعة من الأمور على الاسعوليا

$$
\text { رأسها: }
$$

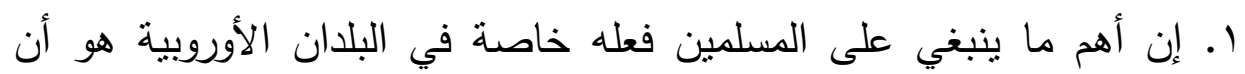

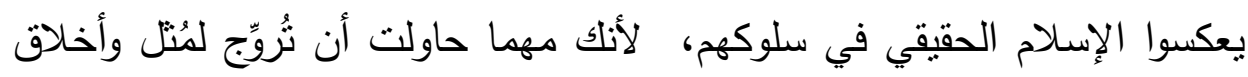

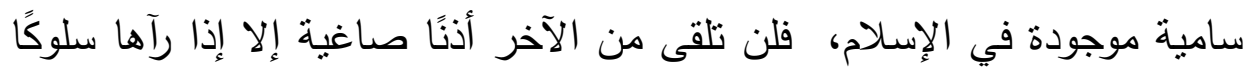

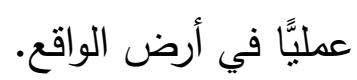

r. يحتاج المسلمون إلى آلة إعلامية تضارع الآلة الإعلامية الغربية، فلا يمكن

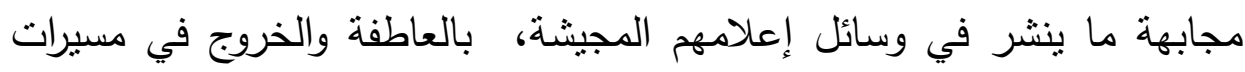
ومظاهرات.. بل لابد من التركيز على إعلام محترف يعمل على التواصل المباشر

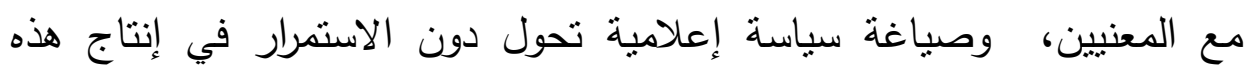

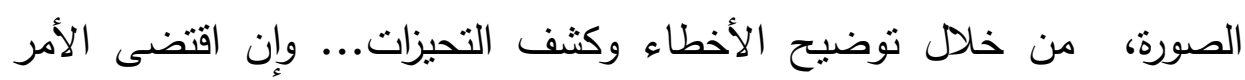
اللجوء إلى القضاء لإيقاف هذه التغطيات المغرضة.

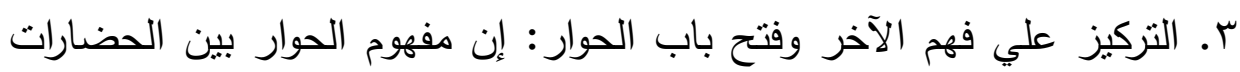

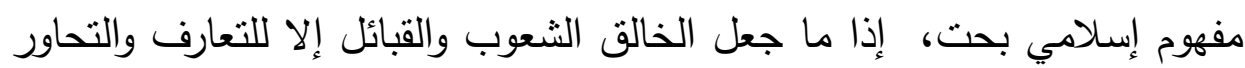

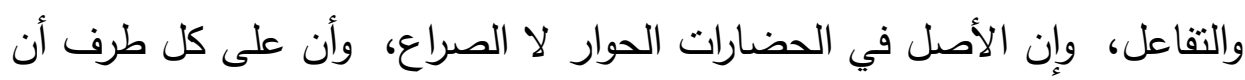

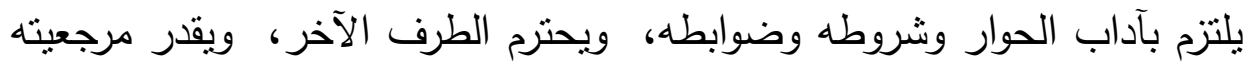

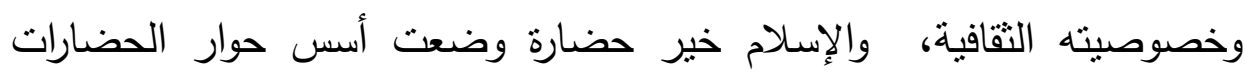

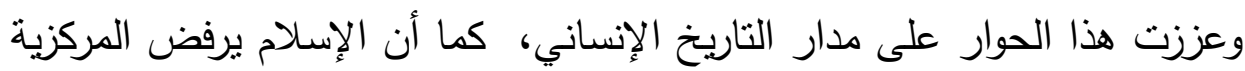

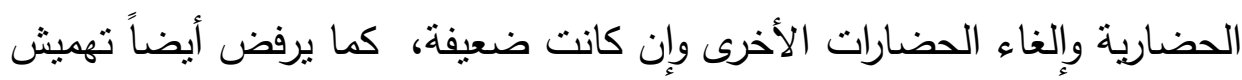

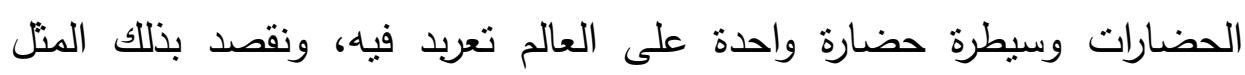

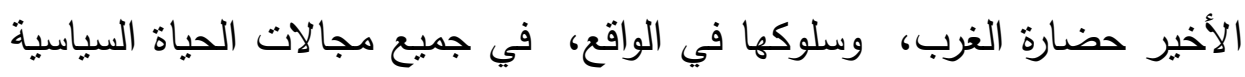


والاقتصادية والأخلاقية. والحوار في الأصل مشروع ؛بل إن الحوار الذي يفيد الطرف الإسلامي على وجه وتترجح مصلحته على مفسدته؛ قال تعالى: (قُلْ بَّا

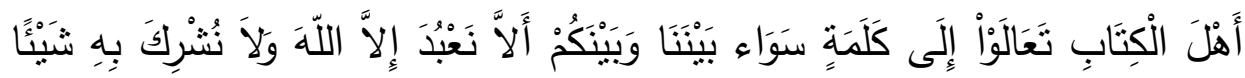

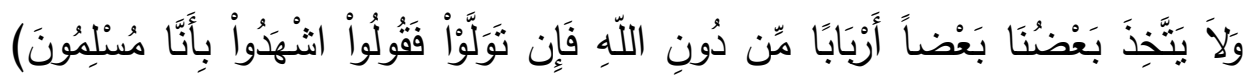

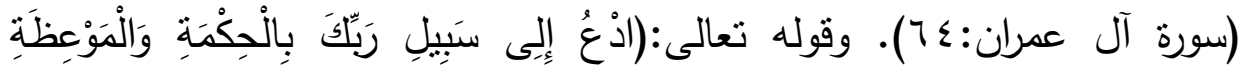

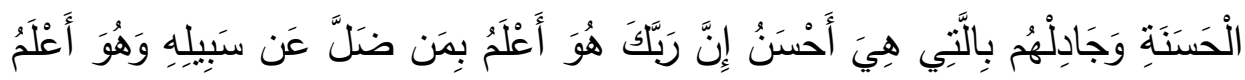

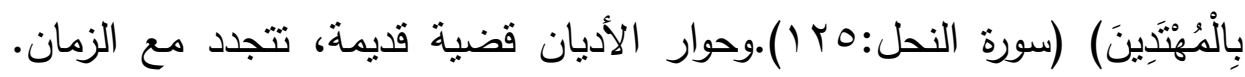

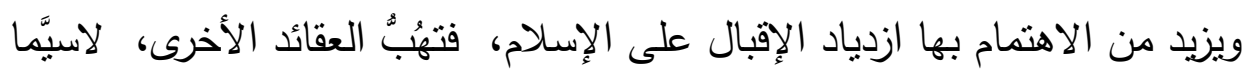

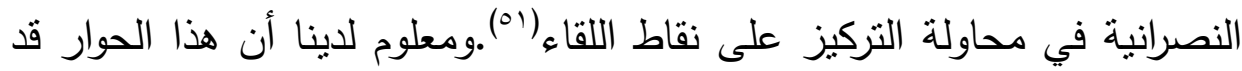

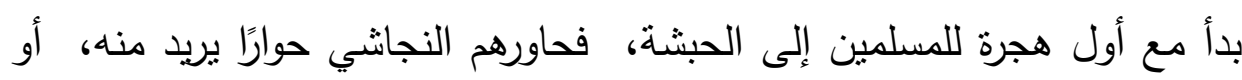

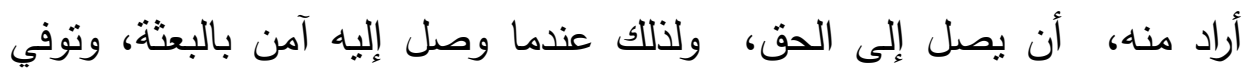
مسلمًا مؤمنًا بالله ورسوله محمَّد (صلى الله عليه وسلم).

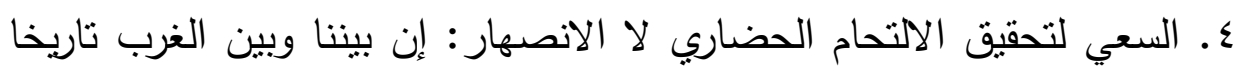

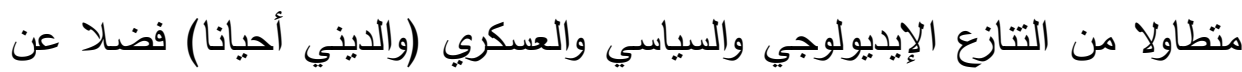

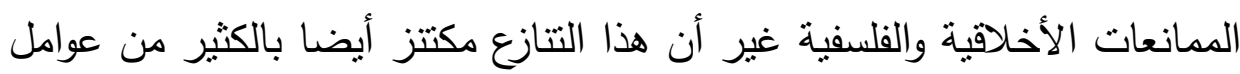

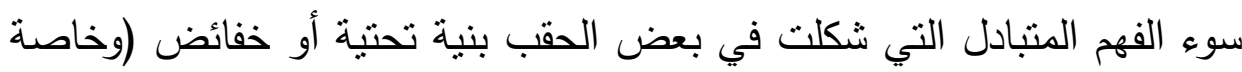

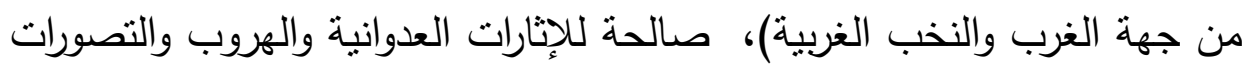
السلبية المقررة سلفا. والدارس الموضوعي، قفبل النتافر والتتاحر السياسيين والإيديولوجيين وبعدهما، ومن الطرفين.

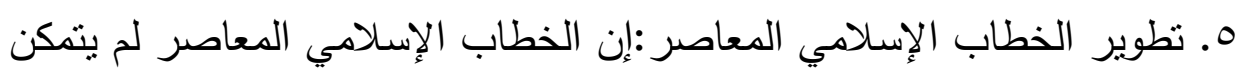

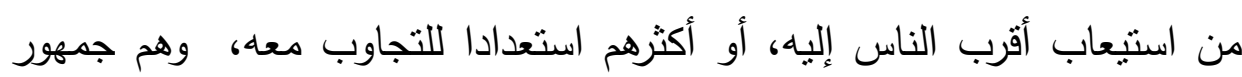

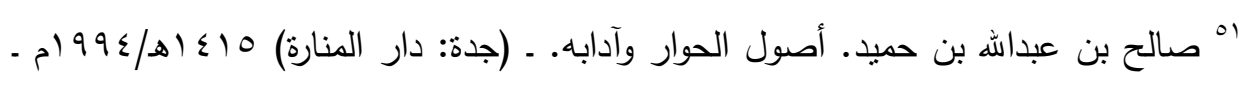
ص. 
المسجد، علاوة عن كسب الآخرين ... فهو خطاب أقرب إلي السلبية، والجزئية،

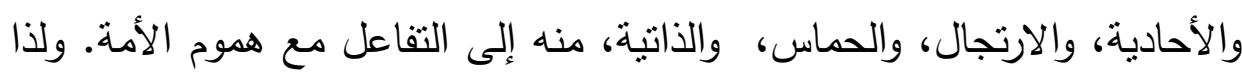

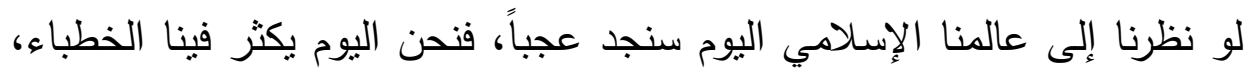

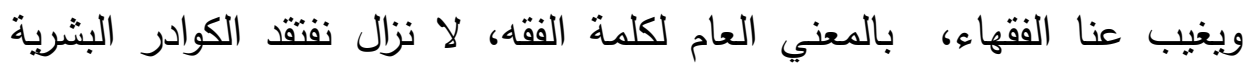

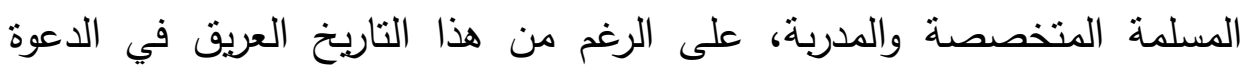
ومسؤولية البلاغ المبين.

أن الخطاب الإسلامي خطاب شامل، يصل إلى الناس على منن الثمولية،

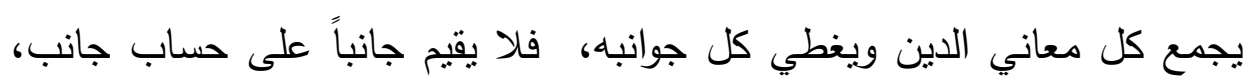

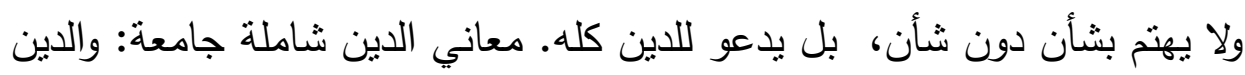

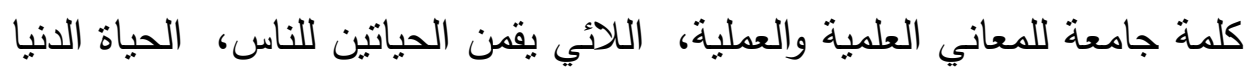

$$
\text { والحياة الآخرة. }
$$

يحتاج المسلمون إلى آلة إعلامية تضارع الآلة الإعلامية الغربية، فلا يمكن

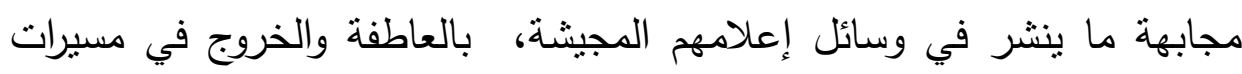

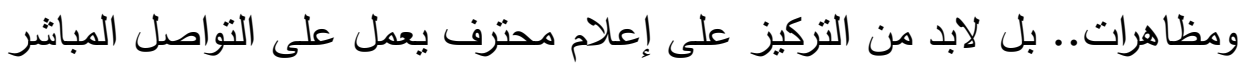

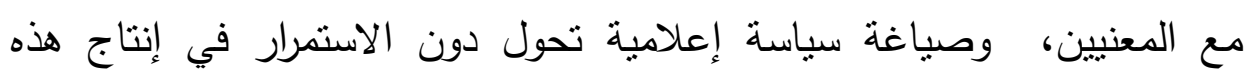

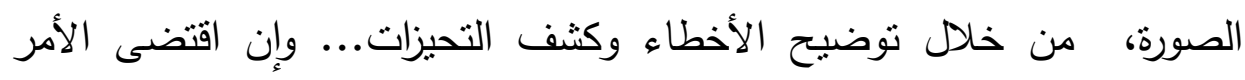

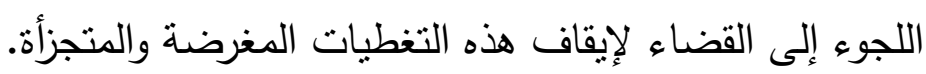

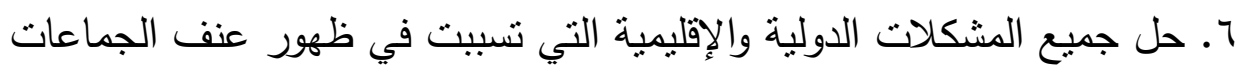

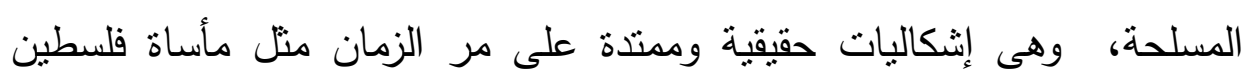
والعراق والصومال.

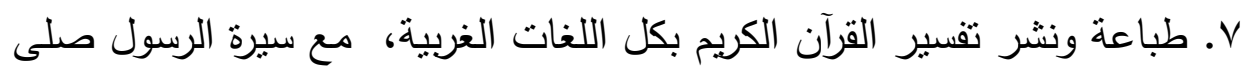

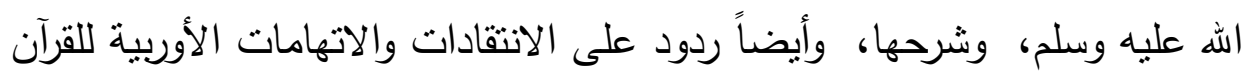

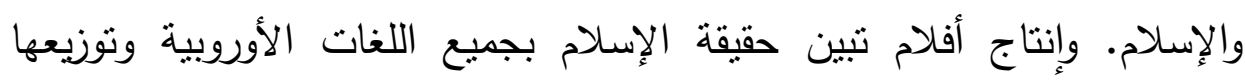


بالماليين على الغربيين بجميع جنسياتهم. إعداد أفلام تسجيلية عن معاناة المسلمين في البوسنة وكوسوفا والثيشان وكثمير وجنوب الفلبين وبورما وغيرها. A. العمل والمناداة بسن قانون دولي يمنع الإساءة للأديان. 


\section{الخاتمة}

وتشثل النتائج والتوصيات: أولاً: النتائج:

ا. الإسلاموفوبيا حاله قديمة بدأت مع ظهور الإسلام، هيث بدأت إرهاصات العداء لصراع الدولة الناثئة في المدينة المنورة.. فالإسلاموفوبيا منواجدة كحالة بين الثرق و الغرب لكنها تأخذ شكلاً جديداً كل عصر .. r. مفهوم الإسلاموفوبيا يمثل أبلغ دلالة على الموقف العام في الغرب تجاه الإسلام والمسلمين، حيث بعكس بشكل عام انتشار نزعة العداء للمسلمين. س. قوة الآلة الإعلامية المعادية للمسلمين مقارنةً بانهيار و تخاذل الآلة الإعلامية المعتمدة على الجهود الذاتية المؤيدة للمسلمين. ع. ضعف الخطاب الإسلامي المعاصر الذي لم يتمكن من استيعاب أقرب الناس إليه، أو أكثرهم استعدادا للتجاوب معه، وهم جمهور المسلمين، علاوة عن كسب الآخرين، فهو لا يتفاعل مع هموم وتطلعات الأمة، ولا يعكس صورة الإسلام الحقيقة. ثانياً: التوصيات:

ا. إن أهم ما ينبغي على المسلمين فعله كلّ في موضعه خاصة في البلدان الأوروبية هو أن يعكسوا الإسلام الحقيقي في سلوكهم ومعاملاتهم. r. علي الدعاة والفقهاء والعلماء وأصحاب الاختصاص أن يدلوا كل واحد منهم

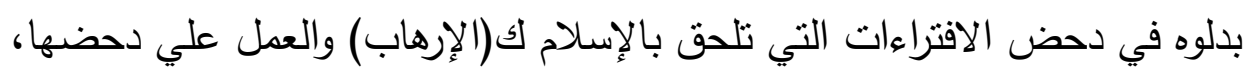
والعمل علي توضيح موقف الإسلام من الإرهاب المذموم، وعدم الخلط بين الجهاد والإرهاب.

r. العمل علي تطوير الخطاب الإسلامي، الخطاب الثامل الذي يصل إلى لى جميع الناس الذي ينطلق من شمولية الإسلام، يجمع كل معاني الدين ويغطي كل 
جوانبه، فلا يقيم جانباً على حساب جانب، ولا يهتم بشأن دون شأن، بل يدعو

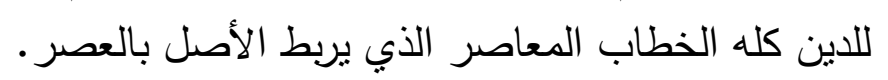

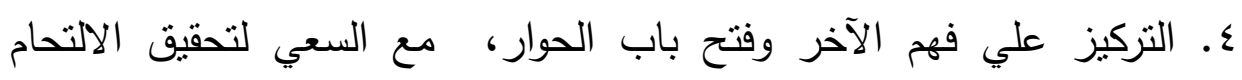
الحضاري لا الانصهار الذي لا يشبه المسلم.

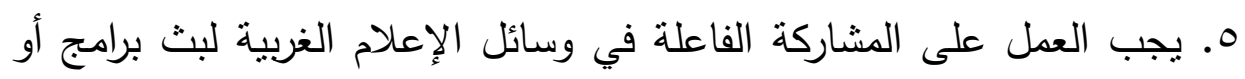
نشر صفحات في جرائد مشهورة مدفوعة الأجر، كما لا ينبغي أن نغفل دور المؤسسات التقافية ودور النشر والترجمة، فهي مطالبة بتوزيع الكتب والنشرات للتعريف بالإسلام بلغات هؤلاء الذين ضللهم الإعلام الغربي ولا نغفل عما قاله المفكرون المنصفون من الغرب فقد مدحوا شريعة الإسلام وقالوا في نبي الإسلام محمد صلّى الله عليه وسلم قولا عادلا محقا فيا حبذا لو جمعت أقوال هؤلاء وترجمت ووصلت إلى العوام من أهل الغرب. 


\section{الهوامش والمراجع:}

ا ـ . ' أستاذ مساعد كلية الدعوة الإسلامية - جامعة ام درمان الإسلامية.

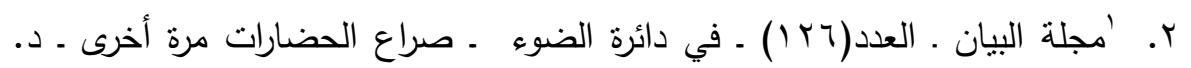

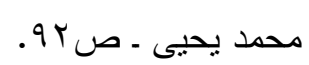

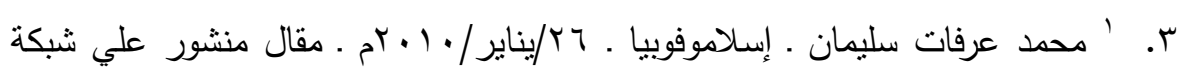

$$
\text { الإنترنت. }
$$

ع. ' ' علاء بيومي . جزور شبكة الإنسلاموفوبيا . مقال منشور علي شبكة الإنترنت .

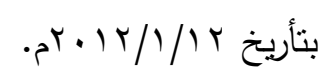

๑. ' أنظر لبعض الكلمات المتعلقة ,كراهية مجموعات من الناس ذات صلية فيما بينها،

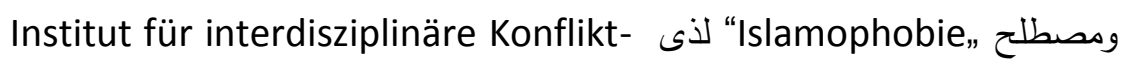
.und Gewaltforschung

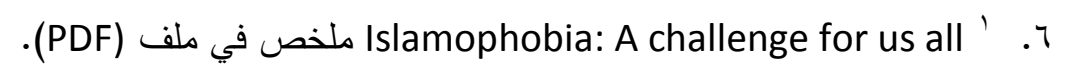

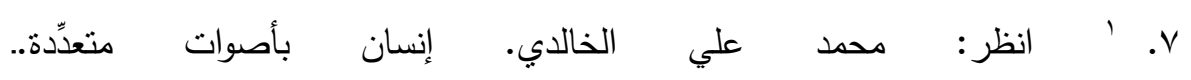

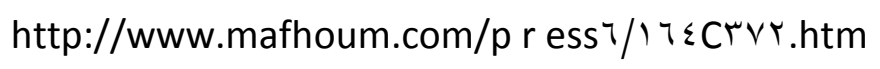

^. ' معتز الخطيب . الغضب الإسلامي ! تفكيك العنف...دراسة نقدية . (دار

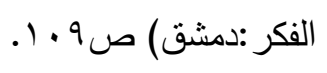

9. ' ' انظر : واصف شديد ـ و سجورد فان كوننغسفيلد . الصورة السلبية للإسلام والمسلمين

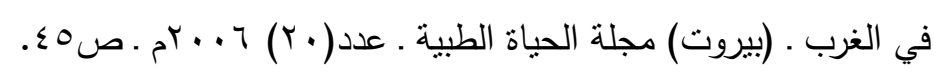

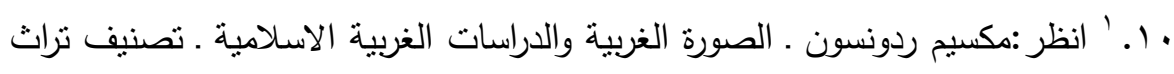

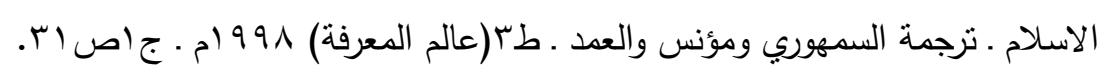

11. 'فرد دونر . اتجاهات الكتابة الغربية عن تاريخ الإسلام قراءة نقدية . (سلطنة عمان)

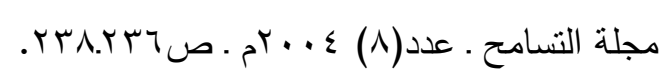

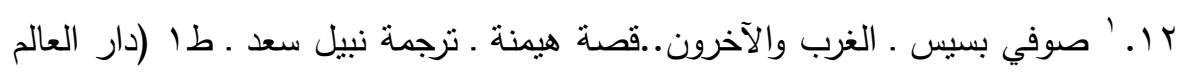

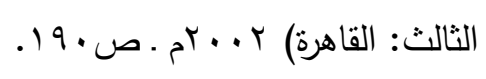

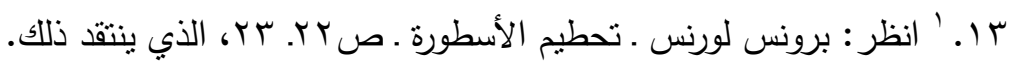

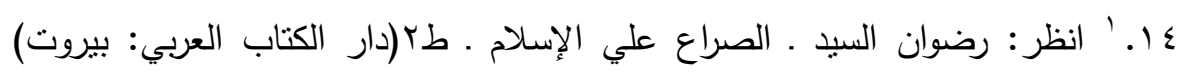

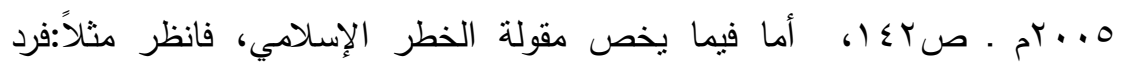


هاليداي ـ الإسلام والغرب.. خرافة المواجهة: الدين والسياسة في الثرق الأوسط، ترجمة عبدالاله النعيمي ـطا (دار الساقي:بيروت)، وجون أسبوزيتو ـ التهديد الإسلامي خرافة أم حقيقة ؟، ترجمة قاسم عبده قاسم ـطا (دار الثروق: القاهرة) r .. r م.

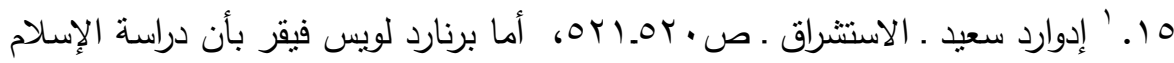

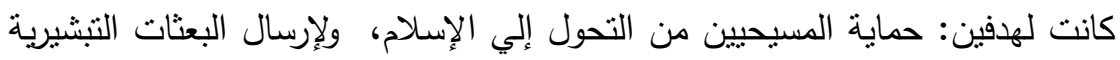

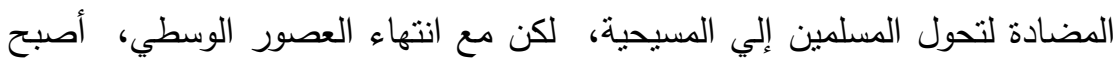

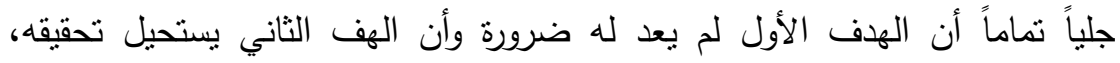

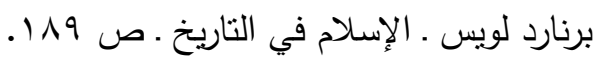
17 . ' انظر : عبدالرحمن بدوي . دور العرب في تكوين الفكر الأوبي . طا (مكتبة الأسرة:

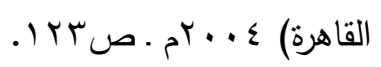

V V ا ' معتز الخطيب ـ مقال بعنوان:(ظاهرة كراهية الإسلام..الجذور والحلول) ـ مجلة نقافتتا

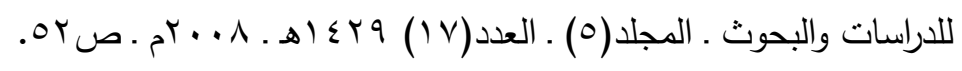

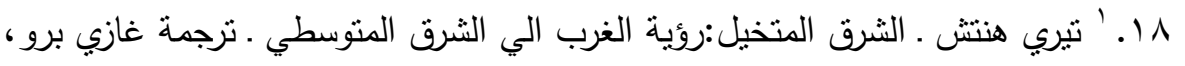

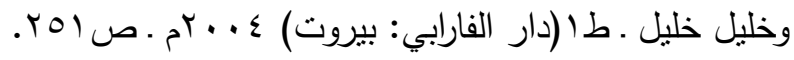

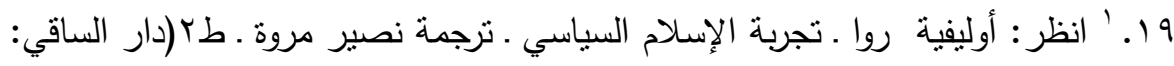

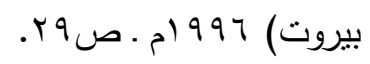

• r. ' انظر : واصف شديد، وسجورد فان ـ الصورة السلبية للإسلام والمسلمين في الغرب .

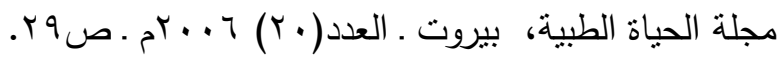

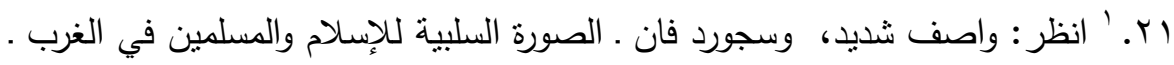

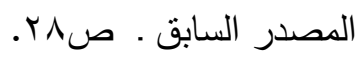

r. r.' محدد البهي . الفكر الإسلامي الحديث وصلته بالاستعمار الغربي (دار الفكر -

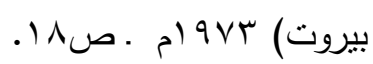

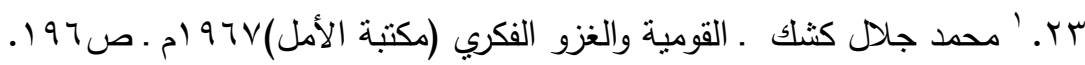

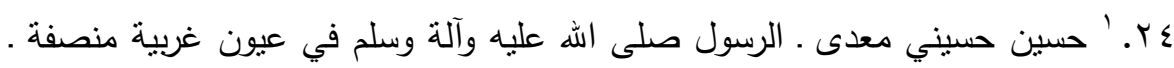

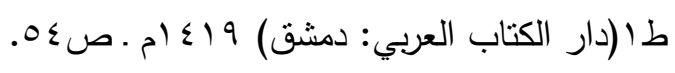

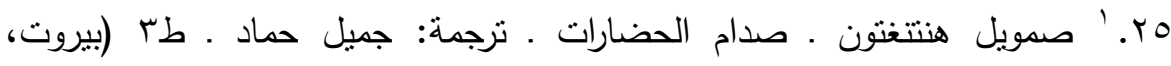

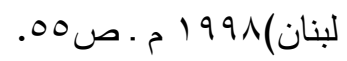


جr.' إيمانويل تود ـ ما بعد الامبراطورية: دراسة في تفكك النظام الأمريكي ـ ترجمة محمد

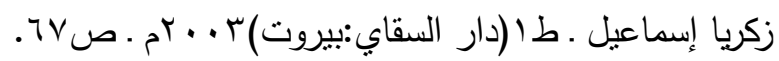

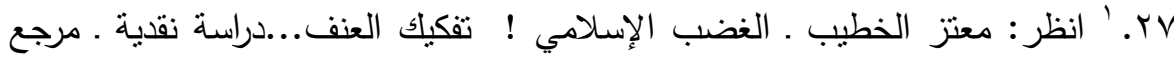

$$
\text { سابق . صVو. } 9 \text {. }
$$

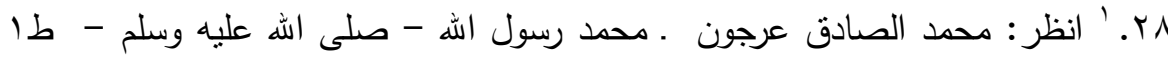

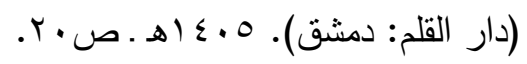

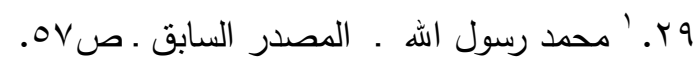

Samuel p. Huntingtonk, who Are we: The Challences to '.r. . Americas Natioal Identity, New york: Simon Schuster r. . ₹

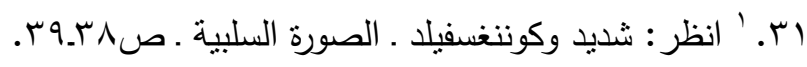

r.' ' فريد هاليداي · ترجمة عبد الاله النعيمي · ساعتان هزتا العالم: (11 أيلول) -

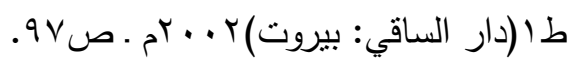

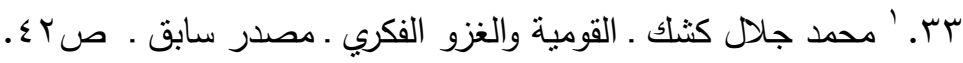

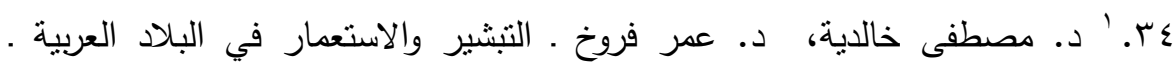

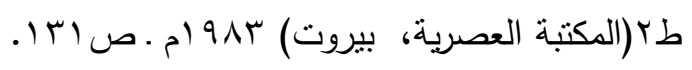

هr. ' ابن منظور (أبو الفضل جمال الدين محمد بن مكرم) ـ لسان العرب ـ المجلد الأول .

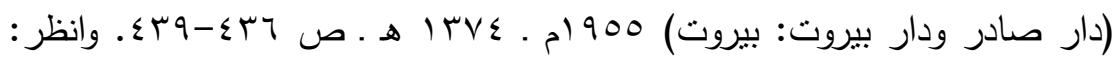

الفيروز آبادي (مجد الدين محمد بن يعقوب) ـ القاموس المحيط ـ ط طب (مؤسسة الرسالة،

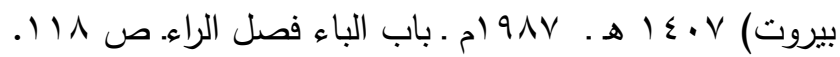

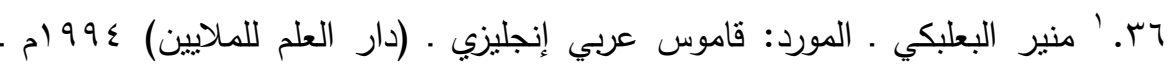

ص.

Vr.' ينظر البيان الصادر من مجمع الفقه الإسلامي برابطة العالم الإسلامي بمكة في

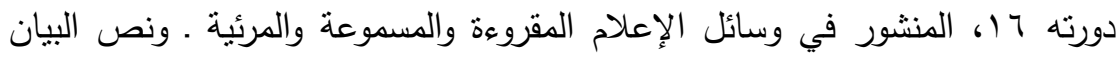

$$
\text { منشور علي شبكة الإنترنت. }
$$

^ـ.' الكلام جزء من مقدمته الجديدة لكتاب الاستشراق . التي نشرتها الجارديان بتاريخ

$$
\cdot 5 r \cdot r / \mu / t
$$




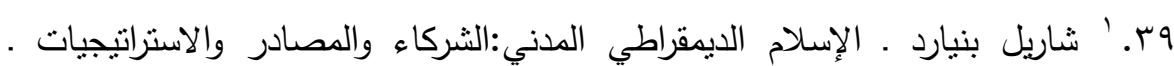

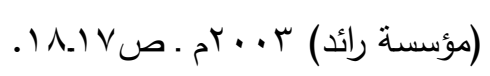

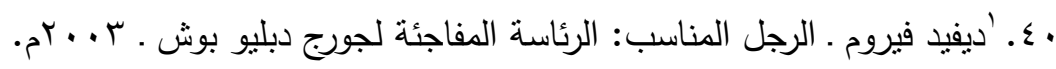

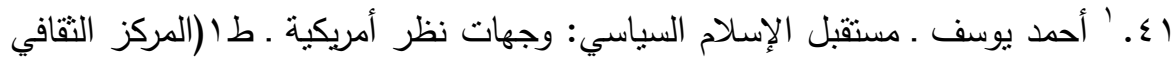

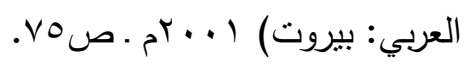

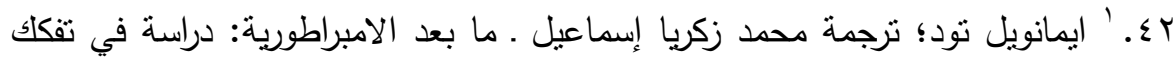

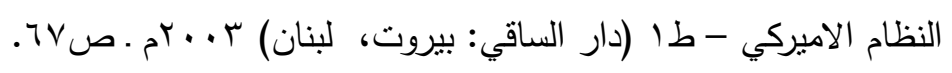

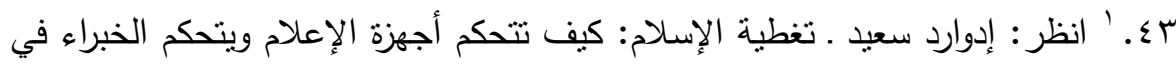

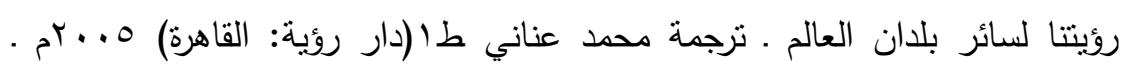

$$
\text { ص ص } 19 .
$$

؟ ـ ' حسين حسيني معدى . الرسول صلى الله عليه و آله وسلم في عيون غربية منصفة

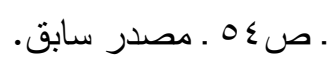

هـ. ' يوسف العاصي إبراهيم الطويل ـ الحملة الصليبية على العالم الإسلامي والعالم

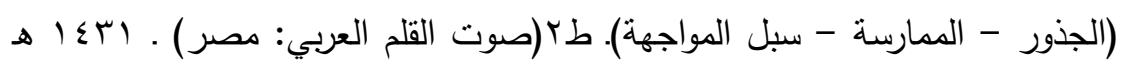

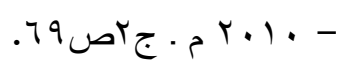

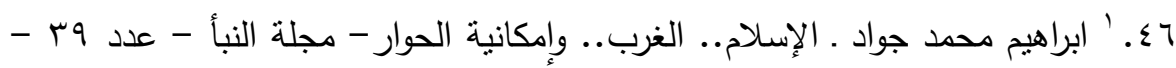

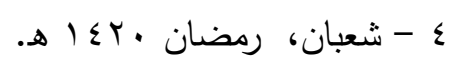

Vـ لـ لم يقتصر هذا الأمر على وسائل الإعلام الغربية، بل أن كثير من وسائل الإعلام العربية تبعتها في ذلك.

^ــ ' يوسف العاصي إيراهيم الطويل ـ الحملة الصليبية على العالم الإسلامي والعالم

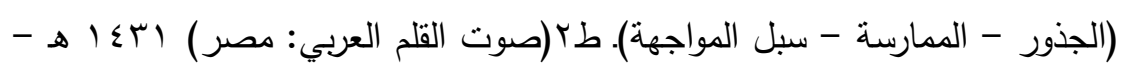

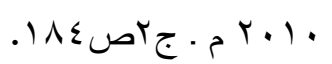

9ء. ' جمع وإعداد علي بن نايف الثحود ـ الخلاصة في فقه الأقليات (1-9) ـ ـ الباحث في

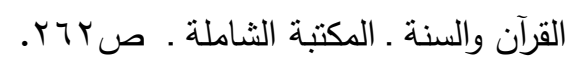

•. ' محمد مسعد ياقوت . نبي الرحمة الرسالة والإنسان . طا (الزهراء للإعلام العربي:

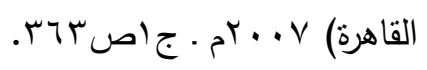


مجلة معالم الدعوة الإسلامية المحكمة - العدد (السابع) - ذو الحجة بـع اهـ/ ديسمبر ع ا ـ rم

10.' صالح بن عبداله بن حميد. أصول الحوار وآدابه. ـ (جدة: دار المنارة)

四 